\title{
Energy-based method for identifying vulnerable macro-elements in historic masonry churches
}

\author{
L. Giresini \\ Department of Architecture, Design and Urbanistic, University of Sassari \\ Palazzo del Pou Salit, Piazza Duomo 6, Alghero (Sassari, Italy). \\ tel. 0799720418 -fax 0799720420 \\ lgiresini@uniss.it
}

\begin{abstract}
Seismic vulnerability of historic churches is a well known issue in earthquake engineering. The need of preserving these buildings encourages the development of reliable numerical methods to assess their seismic behavior. In this paper a new approach is presented, based on evaluating damage pattern obtained by non-linear dynamic analysis and the energy dissipated by each macro-element during earthquakes. A "hierarchy of dissipated energy" concept emerges to give a scale of vulnerability of the parts that compose the church. By modifying masonry mechanical parameters or geometric characteristics, the crack pattern and amount of energy dissipation density of each element is varied and calibrated to achieve the desired hierarchy. The structural designer can therefore state the effectiveness of strengthening devices by checking reduction and possibly migration of dissipated energy density from weaker structural elements to more resistant ones, together with a preferable damage pattern. The proposed strategy is applied to a single nave church, hit by the Emilia Romagna earthquake (Italy, 2012), first defining a scale of vulnerability of the macro-elements and then proposing a rehabilitation strategy, which improves the seismic response in terms of damages and dissipated energy. In the case study the strong vulnerability of the main dome vault was shown, due to the combination of its high dissipated energy density with its intrinsic weakness. Strengthening techniques have been aimed to reduce the amount of dissipated energy of vulnerable macro-elements and to attenuate out-of-plane mechanisms.
\end{abstract}

\section{Keywords}

Churches; historic masonry; energy dissipation; hierarchy of dissipated energy; macro-elements; nonlinear dynamic analysis.

\section{INTRODUCTION}

The seismic vulnerability assessment of historic churches is a meaningful issue for the architectural heritage preservation. The interest on modeling techniques for such complex buildings emerged to objectively evaluate improvement in their seismic behavior after consolidation interventions (Lagomarsino 1998; Lagomarsino et al. 1999; D'Ayala, Speranza 2003). The social and economic repercussions are also relevant themes for the damage assessment in the post-earthquake phase. Statistical analyses on a wide database of surveyed damages in churches were performed (Lagomarsino, Podestà 2004a, 2004b) to forecast the expected damage of churches, characterized by vulnerability indicators. Since numerical modeling of historic masonry structures is a complex task, many approaches were performed in the last twenty years (Lourenço 1996; Roca et al. 2010). Lourenço and Roque (2006) presented a simplified approach for qualitative safety assessment of churches, based on geometric and mechanical indexes. However, the most accepted tool is kinematic analysis on macro-elements, regarded as structurally independent parts of churches (apse, bell tower, façade, etc.). Indeed, often churches are characterized by different construction stages over time; therefore, added parts are not properly connected to the existing ones. Moreover, previous cracks due to earthquakes or static actions produce partitions and structural elements behaving independently. The idea of macro-elements was born and supported from experience of real collapses occurred in masonry churches during strong ground motions (Doglioni et al. 1994). Generally, the evaluation of macro-elements depends on the surveyor experience, therefore on empirical observations based on the investigation on structural connections between elements. In addition, critical aspects should be carefully investigated, e.g. the presence of vaults/arches or different construction stages. Several researchers were focused on the definition of approaches to evaluate the seismic vulnerability by means of limit analysis on rigid blocks 
forming macro-elements. In the method presented by Lagomarsino et al. (1999), first the seismic action is distributed to the macro-elements according to stiffness (if the walls are connected by rigid diaphragms) or to tributary area (deformable floors); afterwards, collapse multipliers are calculated.

For what concerns numerical analysis on finite element models of churches, generally the adopted procedure is to get first information from linear analysis and then to refine the investigation with more sophisticated nonlinear analysis. One of them, the so-called "two steps" procedure, was proposed by Mele et al. (1999): in the first step, the church is analyzed in linear range with a 3D model, to obtain the distribution of horizontal force on each macro-element. In the second step, the macro-elements are separately analyzed up to collapse to evaluate seismic capacity in terms of horizontal strength. Another example is represented by a procedure proposed by Betti and Vignoli ( 2008). Linear static and modal analysis are performed to get some basic information on the global behavior, then nonlinear static analysis is carried out assuming for masonry a smeared cracking constitutive law adopting the Drucker-Prager criterion for compression and Willam Warnke criterion for tensile state. In other cases pushover analysis is shown to be meaningful to support the choice of the more significant macro-elements (Lourenço et al 2011). However, traditional push-over analysis looks not to be a proper tool for irregular buildings like churches and possibly multi-modal approaches should be applied. Recently, Peña et al. (2012) presented a new approach for macro-elements identification, based on the fact that their dynamic response is the same as an independent part or inserted in the whole structure. Nevertheless, modal analysis does not take into account the strong nonlinear behavior of masonry. Moreover, in the methods above-mentioned the distribution of seismic action takes place in an equivalent-static or dynamic way with liner material, while the earthquake is a complex transient action and masonry is a strongly nonlinear material, therefore that makes these assumptions not always reliable. Moreover, the fact of totally neglecting the global behavior in the seismic response, whether only a local analysis is performed, might result in a wrong evaluation of the dynamic behavior, particularly if the church was built in only one stage or is not affected by previous damage. In nonlinear range of 3D analysis, nonlinear transient analyses were also studied and some examples are found in literature (Grimaldi et al. 1992). Finally, nonlinear 3D discrete element models and curved shell finite elements were specifically developed for vaults of historic buildings (Milani et al. 2006; Milani et al. 2008). The latter were applied to churches with pushover and response spectra analysis to automatically evaluate failure mechanisms (Milani 2013). In this paper a new numerical strategy is illustrated, based on the calculation of dissipation energy per unit volume in masonry elements together with plastic strains, under acceleration time-histories applied to the structure. The main purpose is to define a kind of "hierarchy of dissipated energy" (similarly to the well-known "hierarchy of strength"), in order to have a further element of evaluation and better assess the seismic vulnerability of masonry churches.

\section{METHODOLOGY}

The proposed method is based on the definition of a hierarchy of dissipated energy for macro-elements that compose churches. Together with the dissipated energy, a fundamental aspect to take into account is obviously the damage pattern, which provides information about the nature of the considered failure mode, particularly whether it is characterized by out-of-plane or in-plane behavior. In this sense, the current proposal consists of a further check, to add to the other existing safety indicators. The procedure is reported in the flow chart of Fig. 1. First, macro-elements have to be identified according to the traditionally accepted practice for historic churches (Papa et al. 2011). Macro-elements in churches are generally vaults, bell-tower, façade, colonnades, apse, transepts, etc.

Non-linear time-history analyses are performed under seismic records. The resulting damage pattern is investigated by means of the plastic strain vectors distribution, which displays the cracks position. The direction of plastic strain vectors defines whether the considered failure mode is in-plane or out-of-plane. Intrinsically vulnerable are those masonry elements with low thickness with respect to their extension in plan, as they are often subjected to out of plane mechanisms, like thin walls (conventional slenderness higher than 20) or thin vaults, like the "in folio" ones. By contrast, thick elements are generally less vulnerable.-In both cases the-lack of proper connections for horizontal diaphragms/vaults is another key aspect to consider. Anyway the numerical analysis by macro-elements on churches permits the evaluation of the safety level on each single macro-element. 
The dissipated energy of each single macro-element is then considered, adding this aspect to the other ones adopted in the structural analysis (kinematic analysis for out-of-plane mechanisms and displacement based or stress based approaches for global behavior). If intrinsically vulnerable structural elements (such as thin walls or in folio vaults) are subjected to high dissipated energy, this can result in a too high demand for them. By contrast, if their dissipated energy is not relevant (for instance, in comparison with the total average one), they might be classified, from this point of view, as non-vulnerable. Intrinsically non-vulnerable elements (i.e. external thick walls), have a reduced vulnerability with respect to intrinsically vulnerable elements whether subjected to high values of dissipated energy. Indeed, under the hypothesis that the earthquake energy content is the same for a given acceleration time-history, is strongly to prefer to have the dissipation of energy concentrated on in-plane mechanisms (or high DED - Dissipated Energy Density), rather than on out-of-plane or on intrinsically vulnerable elements, as in folio vaults. These considerations are summarized in the flow chart of Fig. 1.

It is important to notice that DED can be also a practical instrument in the hand of the designers to evaluate the efficiency of the connections between macro-elements. For instance, the overturning mechanism of a façade with good connection to transverse walls that dissipates high energy (or is characterized by high DED) is preferable to the same façade that does not dissipates but behaves as rigid body with rocking mechanism. The latter behavior implies more relevant plastic strain vectors which become a key parameter in the proposed method. In this case, considering a set of same out-of-plane mechanisms, higher DED associated to out-of-plane response is a less vulnerable condition than lower DED value.

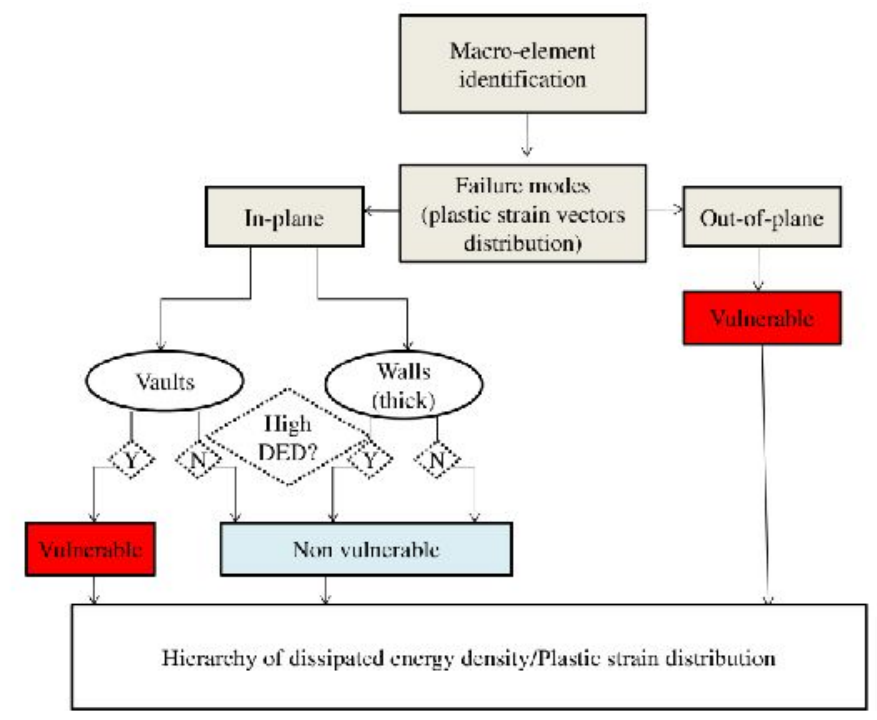

Fig. 1 Energy dissipation based method

Failure modes for arches are not classified neither in-plane nor out-of-plane, but if high DED values are obtained they can be considered vulnerable due to the formation of plastic hinges. Arches are effectively studied by means of limit kinematic or dynamic analysis, where the parts connected by hinges are considered rigid (De Lorenzis et al. 2007).
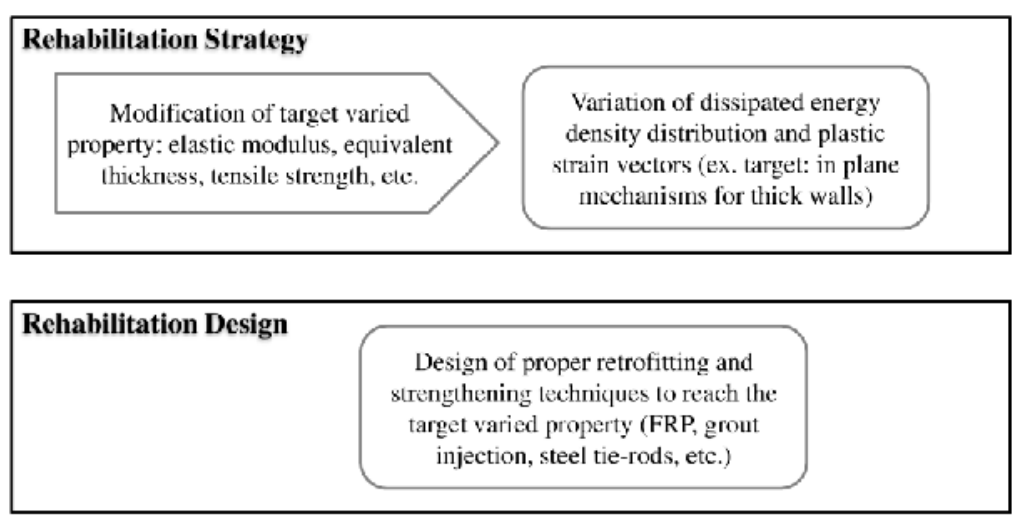

Fig. 2 Rehabilitation strategy and design 
Once that vulnerable and non-vulnerable elements are recognized in a qualitative way, a quantitative approach consists in evaluating the amount of DED for each macro-element. Consequently, a scale of vulnerability emerges, supported both by the damage pattern and by the DED values

A further step could be to state the priority of intervention for the more vulnerable elements. Indeed, strengthening techniques may be adopted to change the distribution of dissipated energy density (DED) in the macro-elements, providing a better distribution of it. The aim would be to reduce and possibly to transfer energy from less to more resistant elements, such are thick walls. The effectiveness of strengthening devices can therefore be quantitatively evaluated. This may be done with a rehabilitation strategy (Fig. 2) consisting in modifying target properties, such as thickness, tensile strengths, fracture energy, etc. to transfer dissipated energy to more resistant elements and to achieve a reduction of out-of-plane response. Once that one or more target properties are identified with an iterative procedure, giving a better DED distribution and damage pattern, the strengthening techniques that guarantee those specific targets have to be designed. The purpose can be accomplished varying the overall seismic response, e.g. with tie-rods to reduce the relevance of out-of-plane mechanisms, or intervening on the material, e.g. adopting FRP on vaults or vulnerable elements to improve the tensile masonry response.

\section{CRITERIA FOR APPLICATION OF THE METHOD}

The proposed numerical strategy is applied to a church case study struck by the Emilia Romagna earthquake (Italy, May 2012). A comparison between the really occurred damages and those predicted by the method is investigated, to validate the model. According to the adopted methodology illustrated in $\$ 2$, the set of macroelements that compose the church is defined. Secondly, a proper choice of mechanical properties and acceleration time-histories has to be performed. Afterwards, by means of nonlinear dynamic analysis, the damage pattern and the evolution of DED for each macro-element are checked on. The total strain energy is automatically calculated by the program and composed by recoverable strain energy, energy dissipated by plastic deformation and energy dissipated by damage. The latter has been chosen as parameter related to the damage, and is dependent on the damage variables $(\S 4)$. These values are then divided by the corresponding masonry volume involved in the dissipation. Plastic strains vectors, orthogonal to the cracks direction, provide information about the in-plane or out-of-plane behavior. Those responses can be investigated with the energybased approach, allowing a seismic vulnerability estimation based on the DED values. Possibly, a modal analysis could be also performed to have a feedback with the nonlinear ones. Analyses are performed with the program Abaqus CAE 6.12 (Abaqus CAE 6.12, User's and Theory Manuals). Implicit procedure is used with the iterative Newton-Raphson method.

\section{CONSTITUTIVE RELATIONS FOR THE EVOLUTION OF DAMAGE}

Masonry is modeled with 3D finite elements with homogenized properties. The nonlinear model, used to perform the proposed approach and suitable for describing the behavior of masonry or frictional materials, is the plastic-damage concrete model presented by Lubliner et al. (1989). The model is implemented in Abaqus CAE 6.12 as Concrete Damaged Plasticity model (Abaqus CAE 6.12, User's and Theory Manuals). Initially born to describe the behavior of concrete material (Lee, Fenves 1998), the model was adapted to masonry (Wawrzynek, Cincio 2005). The post-elastic compression phase is described by an inelastic part with hardening and softening behavior and the tensile one by a brittle behavior with a softening curve (Fig. 3).

The damage evolution is represented by scalar isotropic damaged elasticity which describes the irreversible damage occurring under cyclic loading. The degradation of the elastic stiffness is given by two dimensionsless variables, $d_{t}$ (tensile) and $d_{c}$ (compressive), functions of plastic strains: zero means virgin material, one indicates the total loss of strength and macro-cracks (crushing failure for compression, cracking for tension). The stiffness recovery effects are taken into account with two parameters, $w_{c}$ and $w_{t}$ whose meaning is depicted in Fig. 4. The post-peak behavior for the tensile phase is described by the fracture energy cracking Hilleborg criterion (Hilleborg et al. 1976). Hilleborg et al. defined the energy required to open a unit area of crack, $\mathrm{G}_{\mathrm{f}}$, in the context of brittle failure. In case of masonry, Van der Pluijm (1992) found values of the fracture energy $\mathrm{G}_{\mathrm{f}}$ ranging from 
0.06 to $0.13 \mathrm{Nmm} / \mathrm{mm}^{2}$ for brick tensile strength varying between $1.5-3.5 \mathrm{MPa}$. As well known, the fracture energy and tensile strength of lime mortar brickwork masonry are significantly lower, consequently values of tensile strength $0.05 \mathrm{MPa}$ and fracture energy per unit of surface $0.001 \mathrm{~N} / \mathrm{mm}$ have been used for the as-built configuration.
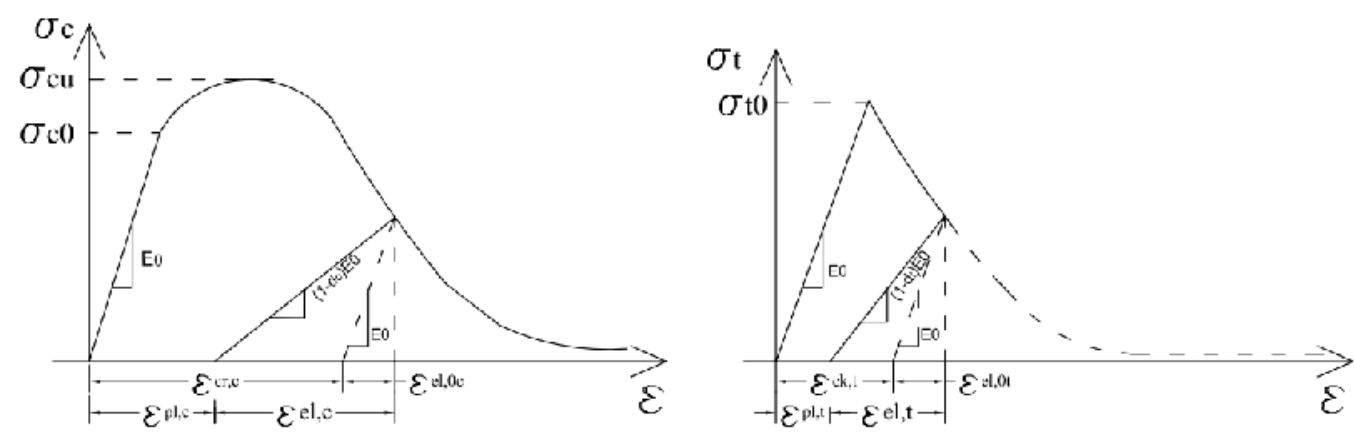

Fig. 3 Constitutive law in compression and tension adopted for masonry - adapted from (Abaqus CAE 6.12, User's and Theory Manuals)

Since the yield functions relates to a flow potential based on the Drucker-Prager hyperbolic function, the following features are required to be set: the dilation angle $\psi$, the flow potential eccentricity, the ratio of initial equi-biaxial compressive yield stress to initial uniaxial compressive yield stress $\sigma_{\mathrm{b} 0} / \sigma_{\mathrm{c} 0}$ and the ratio of the second stress invariant on the tensile meridian to that on the compressive meridian Kc. During the reversal loading, the evolution of plastic deformation determines an irreversible process that dissipates energy.

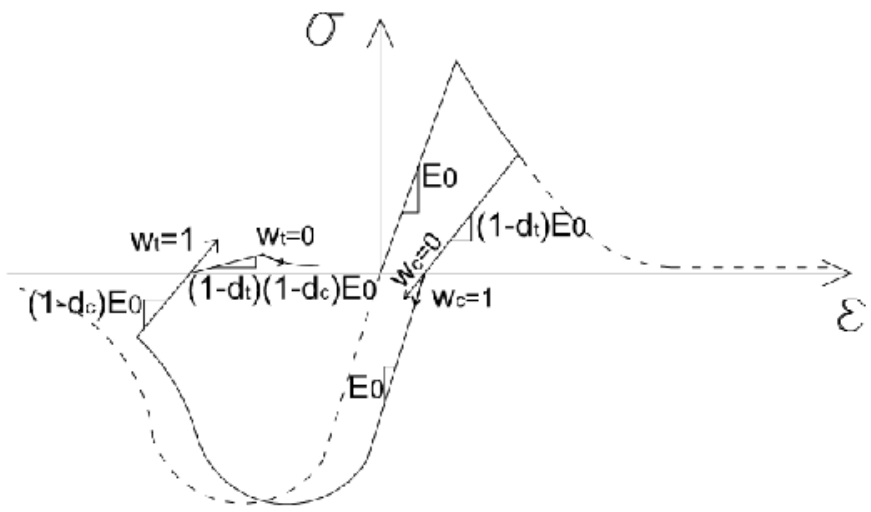

Fig. 4 Cyclic behavior (tension, compression, tension) and stiffness recovery effects adapted from (Abaqus CAE 6.12, User's and Theory Manuals)

The direction of cracking is assumed to be orthogonal to that of the maximum principal plastic strains at the damaged point, used as a measure of the opening and sliding of the crack. In this case study, due to the impossibility of performing experimental destructive tests on masonry, the adopted values are similar to those found in literature for masonry of the same type (clay bricks and mortar (Circ. D.M. 14.01.2008)) properly reduced as will be later illustrated.

\section{ST. VENERIO CHURCH}

\subsection{Geometric and architectural features}

The St. Venerio church is located in the centre of Reggiolo, about $20 \mathrm{~km}$ far from the epicenter of the earthquake that struck the Emilia Romagna Italian region in 2012, May 29 ${ }^{\text {th }}$. The church was built in some constructive stages started in the $11^{\text {th }}$ century, but it was demolished and completely rebuilt in the $18^{\text {th }}$ century, therefore it can be considered as built in an unique phase. The church is isolated and its rectangular plan, $18.6 \times 10.3 \mathrm{~m}$, is constituted by a single nave with central layout (Fig. 5). The main neo-classic façade is oriented to north-west with maximum height of $11 \mathrm{~m}$. 

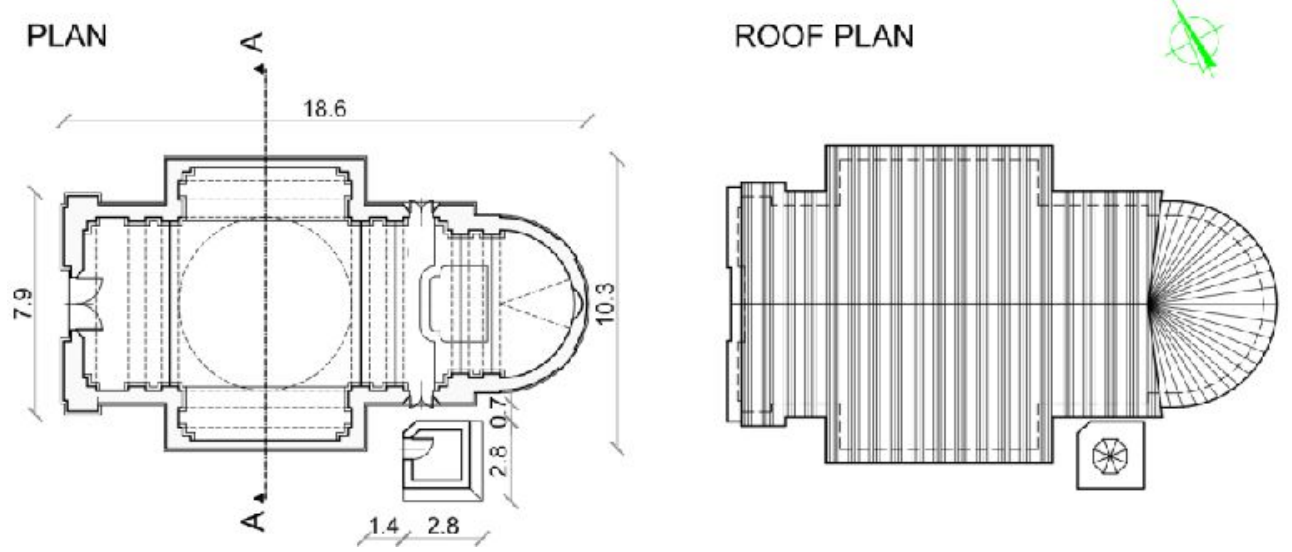

Fig. 5 St. Venerio church: plan and roof plan (measures in $\mathrm{m}$ )

A single-leaf semispherical dome (span about $6 \mathrm{~m}$, rise $3 \mathrm{~m}$ ) covers the central part of the nave; the masonry material is homogeneous mortar and clay bricks, often used in the nearby area for similar historic churches, with units of dimensions 32x16x6 cm. Seven arches, five of them equipped with steel tie-rods, are located at the four sides of the structure. A timber roof, partially collapsed during the earthquake, completes the structure. A bell tower, having plan-dimensions $2.8 \times 2.8 \mathrm{~m}$ in Romanesque style, is structurally independent from the church and therefore not considered in the analysis.

\subsection{Damages caused by the earthquake}

The major earthquake in Reggiolo was on May, $29^{\text {th }}$ and caused severe damages to large parts of the building. The collapse of the central dome vault (Fig. 6) was probably originated by its low thickness $-6 \mathrm{~cm}$, in folio type - and by the strong vertical acceleration component which characterized this seismic shock.

The façade was subjected to two types of failures: an in-plane shear mechanism, which caused the typical Xshaped cracks at the spandrel above and below the small opening (Fig. 7(a), (b)), together with an incipient overturning of the upper part of the façade (Fig. 7(c)), probably due to ineffective connections with longitudinal walls. No overturning mechanism was observed in the tympanum.

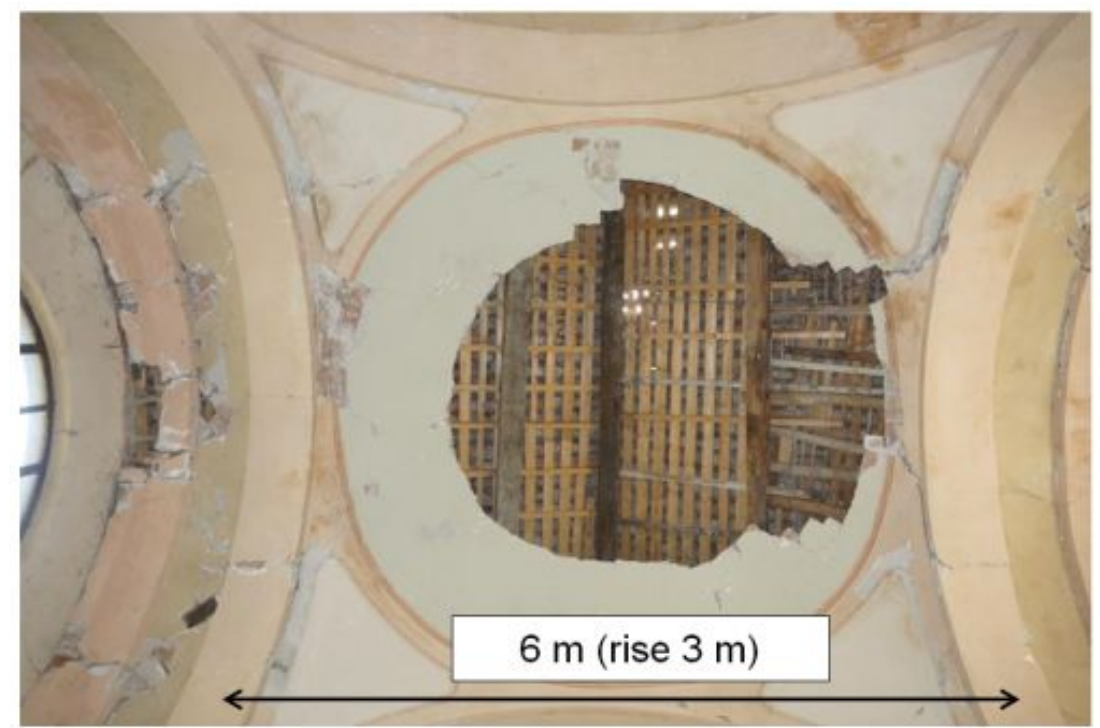

Fig. 6 Collapse of the central dome vault

The apse suffered a severe overturning mechanism with the partial collapse of the vault wedge, $6 \mathrm{~cm}$ thick. The dynamic activation of the apse is due to previous damages, since a restored crack is still visible in the central part of the apse wall (Fig. 8). 

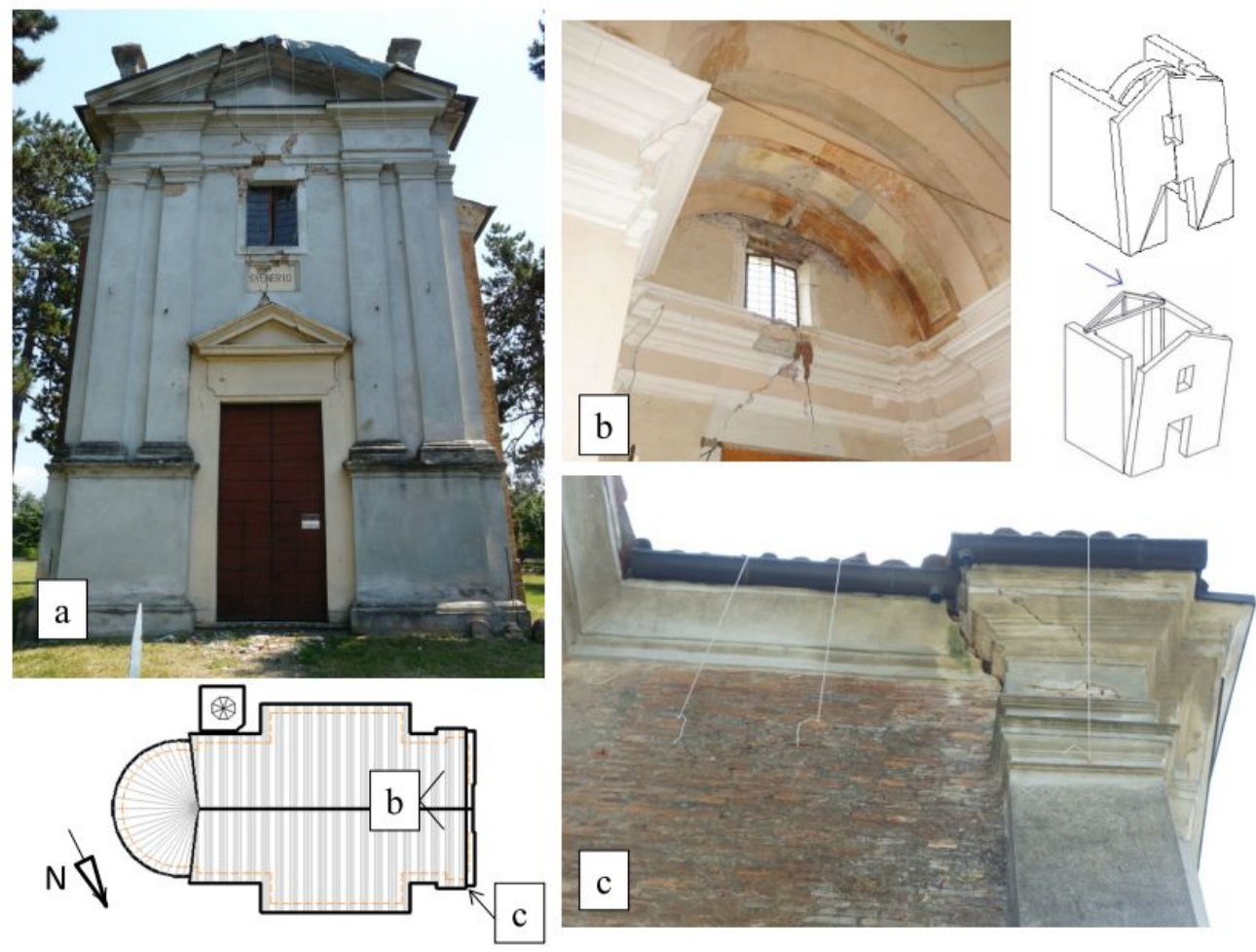

Fig. 7 In-plane shear mechanism (a,b) and out-of-plane overturning mechanism (c) of the main façade

Damages at left and right walls (called respectively "left chapel" and "right chapel" in the following pages) are also widespread, especially at the upper corners of the right wall and in the internal keystone of the adjacent arch (Fig. 9). Moreover, those mechanisms could permit a cross-evaluation of experimented PGA according to (Sassu et al. 2012). Based on this method, the calculation of the collapse multiplier of the main façade confirmed the value of the peak ground acceleration recorded by the accelerometers. Indeed, the collapse multiplier is lower than the acceleration experienced by the façade.
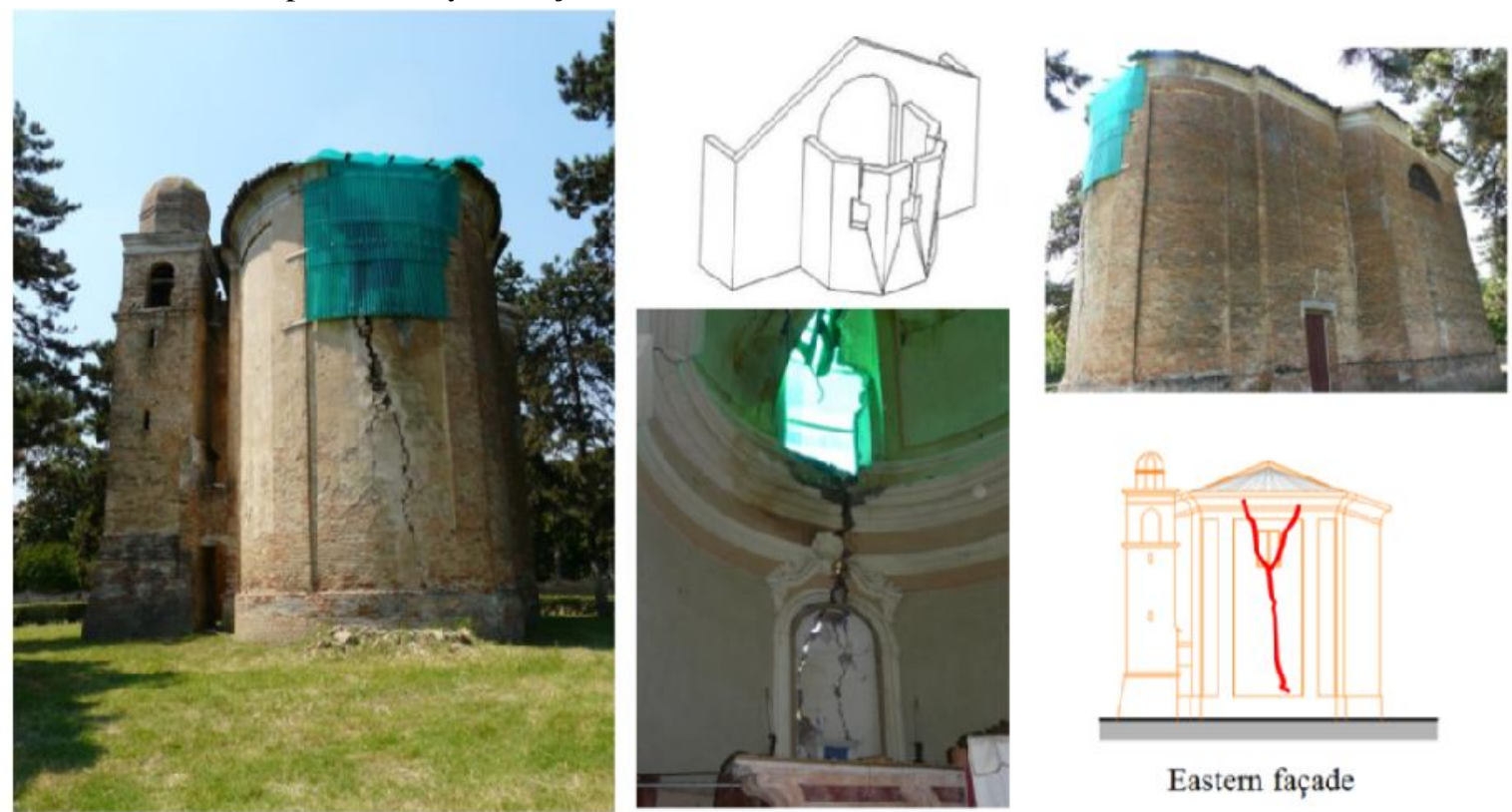

Eastem façade

Fig. 8 Overturning mechanism of the apse 

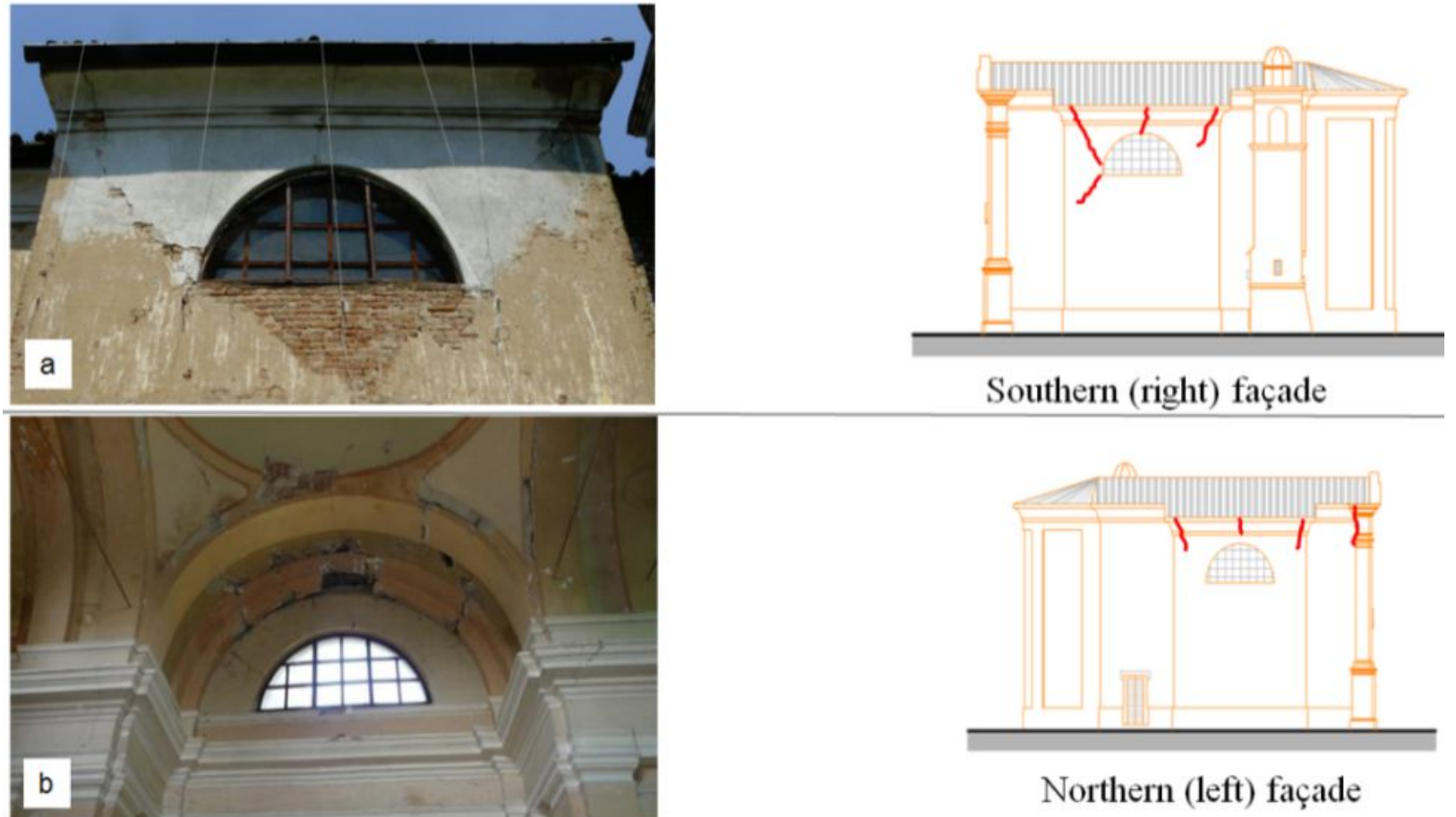

Northern (left) façade

Fig. 9 In-plane and out-of-plane response of right (a) and left (b) chapels façades

\subsection{Finite element model and material definition}

The church has been analyzed with a finite element model with homogeneous material formed by 18148 nodes, 5852 quadratic quadrilateral S8R and 165 triangular STRI65 shell elements (Abaqus CAE 6.12, User's and Theory Manuals) (Fig. 11).

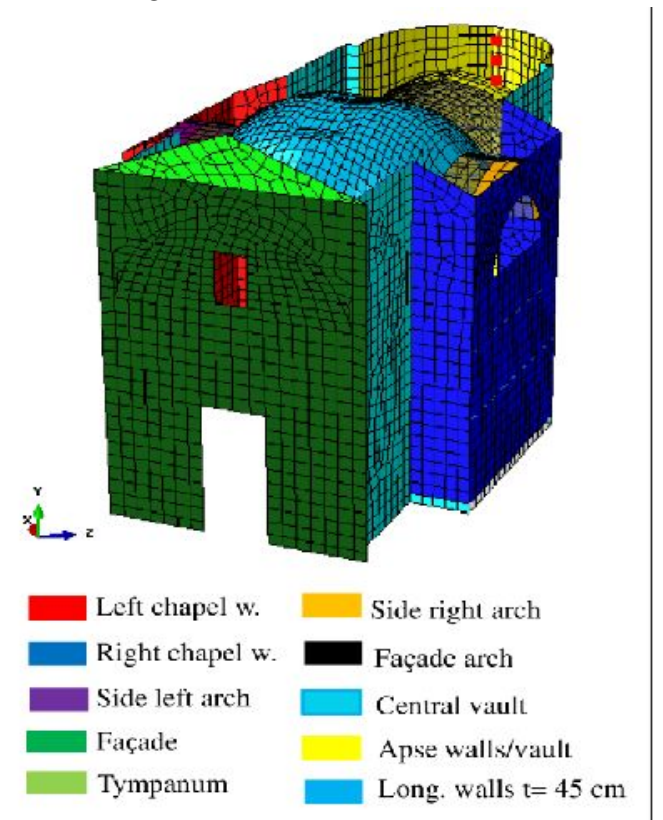

(a)

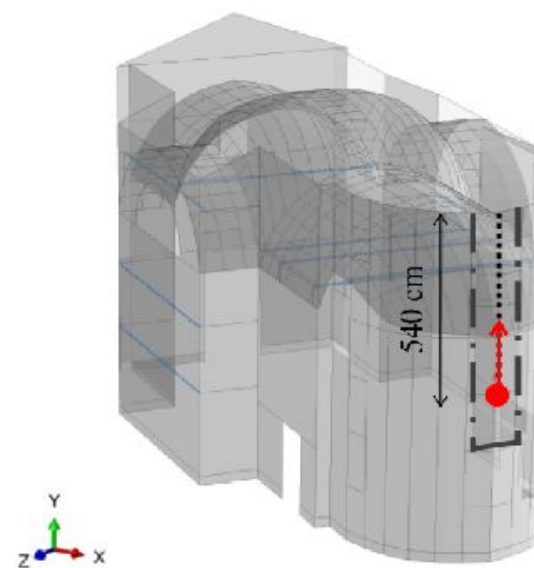

Pre..... Pre-existing crack

$\longrightarrow \quad$ Unit vector in the virtual crack extension

- Crack tip

(b)

Fig. 10 Macro-elements in the finite element model (a) and pre-existing crack in the apse (b) 


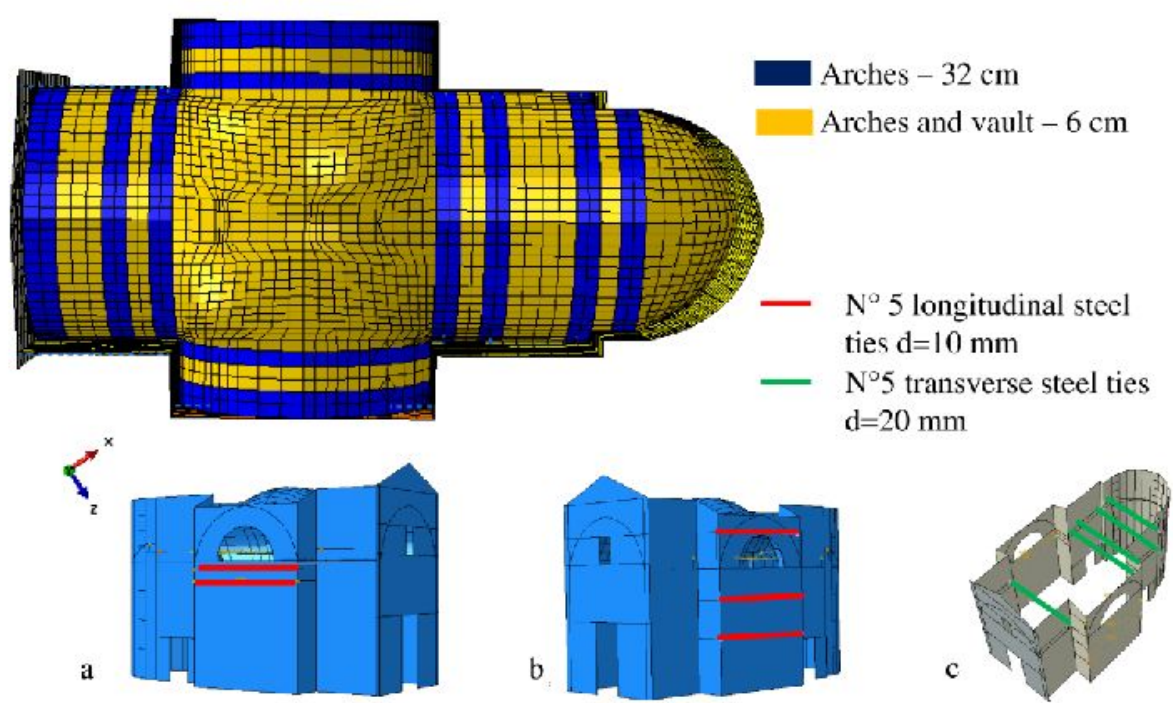

Fig. 11 Arches and vaults features, longitudinal steel ties in the (a) left and (b) right façades and (c) transverse steel ties

Shell elements have 9 integration points through the thickness, and being the mesh size $30 \mathrm{~cm}$, their characteristic length is $35.5 \mathrm{~cm}$. The vaults and arches infill was modeled only in terms of seismic mass, by adopting a specific weight equal to that of masonry and up to an inclination of $30^{\circ}$ with respect to horizontal plane at imposts. Timber roof was also modeled as equivalent mass. The total mass of the model is 493.3 tons.

Table 1 Mechanical properties for CDP based material, St.Venerio church (see $\S 4$ for symbols).

\begin{tabular}{|c|c|c|c|c|c|c|c|}
\hline & $\begin{array}{c}\mathrm{E}_{0} \\
(\mathrm{MPa})\end{array}$ & $\begin{array}{c}\sigma_{\mathrm{cu}} \\
(\mathrm{MPa})\end{array}$ & $\begin{array}{c}\sigma_{\mathrm{t} 0} \\
(\mathrm{MPa})\end{array}$ & \multicolumn{2}{|c|}{$\begin{array}{l}\text { Compressive } \\
\text { damage }\end{array}$} & \multicolumn{2}{|c|}{ Tensile damage } \\
\hline & 2000 & 4 & 0.05 & $\mathrm{~d}_{\mathrm{c}}$ & $\varepsilon_{\mathrm{c}}^{\text {in }}$ & $\mathrm{d}_{\mathrm{t}}$ & $\varepsilon_{\mathrm{t}}^{\mathrm{ck}}$ \\
\hline \multicolumn{4}{|c|}{ Fracture energy $=0.001 \mathrm{~N} / \mathrm{mm}$} & 0 & 0 & 0 & 0 \\
\hline $\begin{array}{r}\Psi \\
\left({ }^{\circ}\right)\end{array}$ & Eccentricity & $\sigma_{\mathrm{b} 0} / \sigma_{\mathrm{c} 0}$ & $\mathrm{~K}_{\mathrm{c}}(-)$ & \multirow{3}{*}{$\begin{array}{l}0.231 \\
0.429 \\
0.950\end{array}$} & \multirow{2}{*}{$\begin{array}{l}0.001 \\
0.005\end{array}$} & 0.82 & 7.5E-4 \\
\hline 20 & 0.1 & 1.16 & 0.667 & & & $\mathrm{w}_{\mathrm{c}}$ & $\mathrm{w}_{\mathrm{t}}$ \\
\hline & & & & & 0.09 & 1 & 0 \\
\hline
\end{tabular}

In Fig. 10 the existing steel ties are displayed: the longitudinal ones are asymmetric with a diameter of $10 \mathrm{~mm}$, while the transverse ones, with a diameter of $20 \mathrm{~mm}$, are concentrated in the apse zone. They are modeled in Abaqus as CONN3D2 elements. An existing crack in the apse (Fig. 8) was inserted in the model as initial crack, since it was present before the earthquake (Fig. 10). The calculation has been performed by means of the classical Rice J-integral, from Fracture Mechanics.

The base nodes are fixed to the ground at the translational DOFs, and a lower band, $30 \mathrm{~cm} \mathrm{high,} \mathrm{is}$ characterized by a linear elastic material to avoid unreasonable stress concentration which could invalidate the damage evolution. After the step related to the self-weight, the three translational DOFs at the base were released to assign acceleration histories. The building geometry is rotated about the vertical axis of $34^{\circ}$ clockwise, to correctly assume the accelerations along West-East and North-South directions. Nine acceleration time-histories, namely three by three main directions, have been used in the calculation and are displayed in Fig. 12. The calculation time was about 15 hours for the as-built model in the initial configuration (8GB RAM).

The parameters of the Concrete Damaged Plasticity model are reported in Table 1. More in detail, the initial elastic modulus $\mathrm{E}_{0}$ and the compressive strength $\sigma_{\mathrm{cu}}$ are obtained from the Italian code for existing masonry (mortar and clay brick). The Young modulus is equal to $2000 \mathrm{MPa}$ and the Poisson coefficient 0.20 (NTC2008). The tensile strength has been supposed from the outcomes of experimental tests performed by Schubert (Schubert 1988), who obtained a ratio between the tensile and compressive strength ranging from 0.03-0.1. The fracture energy value is taken from the Van der Plujim results (Van der Pluijm 1992). By fixing the value of tensile strength, the fracture energy value is obtained with a linear extrapolation of the reported values, even 
though the tensile strength hereby conserved is considerably lower than the minimum obtained by Van der Plujim (1.5 MPa). The dilatancy angle has been taken equal to $20^{\circ}$ resulting in $\tan 20^{\circ}=0.325$, considering values suggested by (Lourenço 1996). All the remaining parameters of Table 1 have been posed as default or suggested values for brittle materials (Abaqus CAE 6.12, User's and Theory Manuals). However, it has to be pointed out that the interest is not strongly focused on precise values of mechanical properties, but the attention is concentrated in the use of dissipated energy for each element in comparative sense, between the as-built and the rehabilitated configuration.

\subsection{Seismic records}

The case study is located in the area hit by the 2012 Emilia earthquake, particularly near Reggiolo, a small village close to the epicenter of the two main shocks (May, $20^{\text {th }}$ and $29^{\text {th }}$ ). The natural acceleration time-histories registered in three stations, Mirandola (MRN), Moglia (MOG0) and Novellara (NVL) are considered (Fig. 12, Table 2 Acceleration time histories characteristics (Accelerograms Database of seismic shocks on May, 29th2012, Emilia Romagna region (Italy). Department of Italian Civil Protection 2012)), referring to the May $29^{\text {th }}$ shock, which caused relevant damages in the church. Since no sufficient information was available on the soil characteristics, the natural accelerograms have not been elaborated and used as they are, because Reggiolo is located between the considered stations. Nearby the village, many other historic masonry buildings were severely struck by that earthquake (Andreini et al. 2014). It is worthy to notice the relevant vertical component of the strongest acceleration time-history, MRN, with a peak of about $0.8 \mathrm{~g}$ at $3.93 \mathrm{sec}$. The peak of the MOG0 is instead for the component West-East with a value of $0.23 \mathrm{~g}$ at $10.9 \mathrm{sec}$. PGA are about $0.21 \mathrm{~g}$ and $0.24 \mathrm{~g}$ for MRN and MOG0 respectively, and 0.06g for NVL (West-East direction). All the acceleration time-histories are simultaneously applied to the models to simulate the real earthquake, taking into account the actual position of the church in terms of the angle between East-West and longitudinal axis of the church.

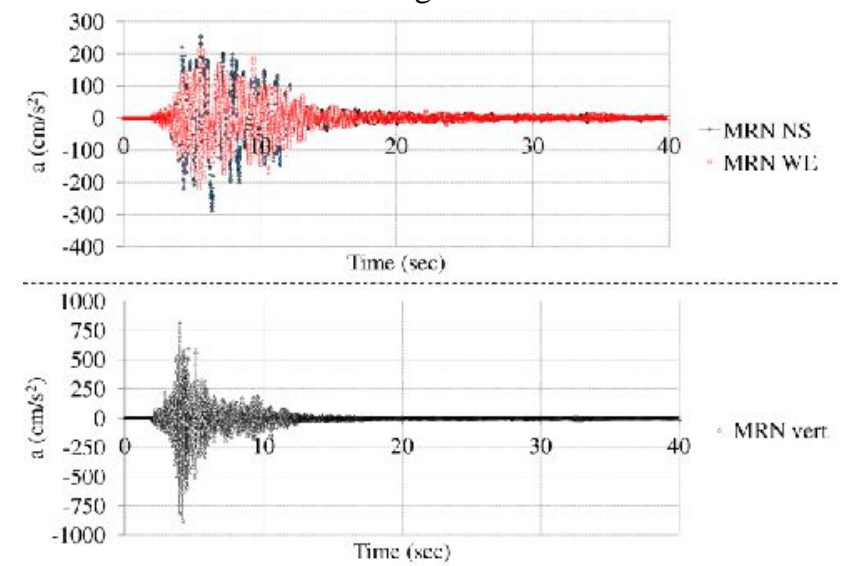

(a)

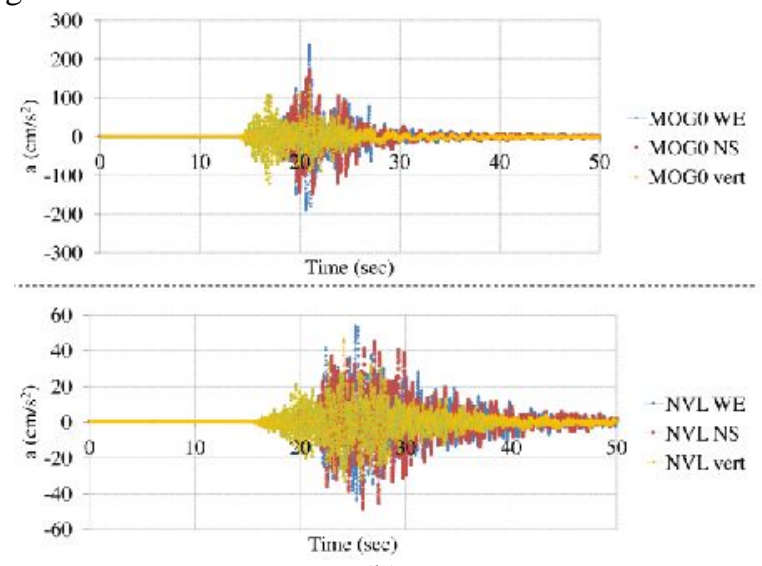

(b)

Fig. 12 Acceleration time-histories used in the transient analysis: (a) Mirandola record; (b) Moglia and Novellara records

Table 2 Acceleration time histories characteristics (Accelerograms Database of seismic shocks on May, 29th2012, Emilia Romagna region (Italy). Department of Italian Civil Protection 2012)

\begin{tabular}{|c|c|c|c|c|c|c|c|c|c|c|}
\hline Event name & Date & MW & Station & $\begin{array}{c}\text { Soiltype } \\
\text { (EC) }\end{array}$ & $\begin{array}{c}\text { Comp } \\
.\end{array}$ & $\begin{array}{l}\text { PGA } \\
(\mathrm{g})\end{array}$ & $\begin{array}{l}\text { Depth } \\
(\mathrm{km})\end{array}$ & $\begin{array}{l}\mathrm{PGV} \\
(\mathrm{m} / \mathrm{s})\end{array}$ & $\begin{array}{l}\text { PGD } \\
(\mathrm{cm})\end{array}$ & $\begin{array}{l}\text { Repi } \\
(\mathrm{km})\end{array}$ \\
\hline NVL & 05-29-2012 & 6.0 & Novellara & $\mathrm{C}$ & E-W & 0.055 & 10.2 & 0.0257 & 7.68 & 28.0 \\
\hline MRN & 05-29-2012 & 6.0 & Mirandola & $\mathrm{C}$ & E-W & 0.212 & 10.2 & 0.2851 & 9.14 & 4.1 \\
\hline MOG0 & $05-29-2012$ & 6.0 & Moglia & $\mathrm{C}$ & E-W & 0.236 & 10.2 & 0.266 & 3.75 & 16.4 \\
\hline
\end{tabular}

\section{EXAMPLE OF APPLICATION OF THE METHOD}

The analysis is performed by following the steps of the procedure described in $\S 2$. The second step, related to the failure modes identification, is also used to perform a comparison between the real damages and those reproduced by the numerical model to validate it. 


\subsection{Macro-elements identification}

According to the classification proposed by Papa et al. (2011) and Lagomarsino et al. (1999), the macroelements of the St. Venerio church have been identified (Fig. 10(a)): central vault, main façade, left and right chapels, namely the longitudinal walls $30 \mathrm{~cm}$ thick, apse walls and vault, side left and right arches, arch adjacent to the façade, longitudinal walls $45 \mathrm{~cm}$-thick and tympanum. The remaining arches have not been considered since their contribution to the overall dissipated energy and the damages are limited. The behavior of the longitudinal $45 \mathrm{~cm}$-thick walls is about the same for the left and right side, therefore results are provided only for one side. Finally, the façade in Fig. 10(a) includes the tympanum volume, also considered as separated macroelement.

\subsection{Failure modes analysis}

A comparison was made in terms of damage pattern for the church under examination. The failure modes predicted by the numerical model are similar to those experienced the real church (Table 3) and are compared to those generally proposed for churches (Lagomarsino et al. 1999; Papa et al. 2011). The distribution of the plastic strain vectors reproduces real damages allowing to distinguish out-of-plane and in-plane mechanism, as requested in the second step of the procedure $(\S 2)$. More in detail, the central vault is subjected to a shear mechanism that causes its collapse; the plastic strain vectors demonstrate that the damage is concentrated in the pendentives and in the adjacent arches, from which the vault detaches. A deficiency of the model stands in the fact that it does not reproduces the vault collapse due to the damage evolution in adjacent finite elements. Moreover, due to the perfect contact between finite elements, the model is not able to recreate possible preexisting detachments. The so called "right and left chapels" walls are mainly subjected to out-of-plane mechanisms at the corner, where there is a geometric masonry discontinuity (northern wall) and a detachment of the wall from the adjacent arch. The apse is characterized by an overturning mechanism partially due to the crack existing prior to earthquake. In-plane and out-of-plane mechanisms are recognized for the main façade.

The external longitudinal walls, $45 \mathrm{~cm}$-thick, do not present significant in-plane damage, but only micro-cracks effectively reproduced by the high DED value. The horizontal plastic strain vectors reported in Table 3 for this macro-element indicate the out-of-plane mechanism of the $30 \mathrm{~cm}$-thick intersecting walls. Finally, the analysis does not suggest any overturning mechanism of the tympanum, as actually occurred.

It can be observed that the approach based on finite element models does not allow the evaluation of local mechanisms, which could provide further information on the seismic response of the building. For instance, after the crack in the façade formed, kinematic or rocking analysis could be performed to assess the vulnerability of the macro-element to the local phenomenon.

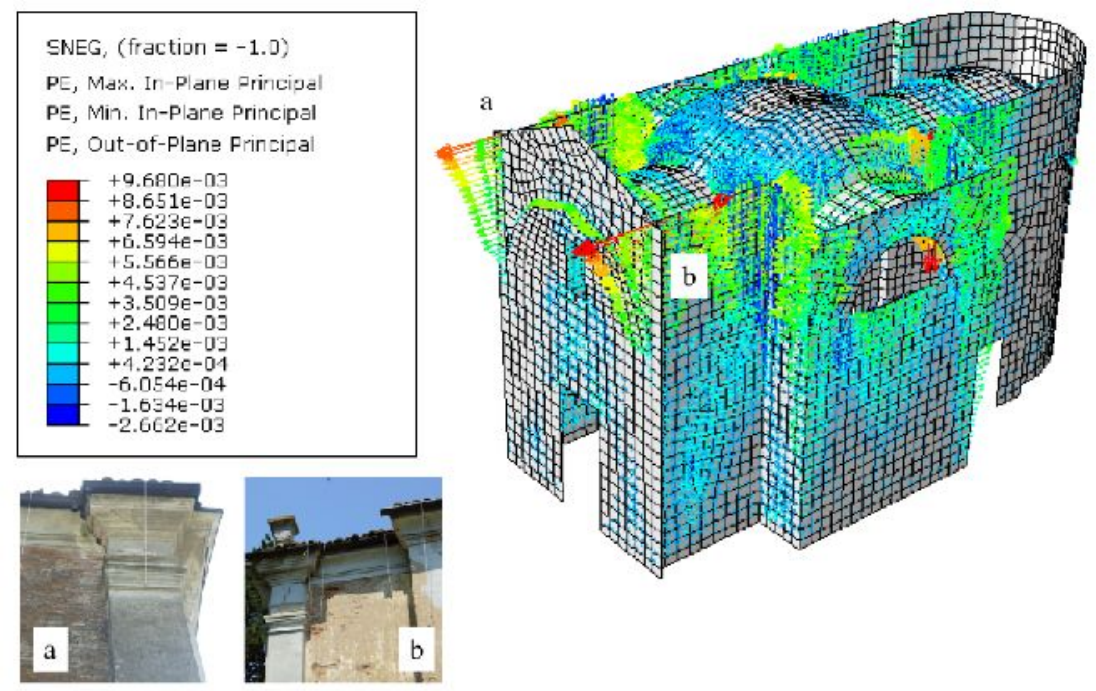

Fig. 13 Final plastic strain vectors distribution at the integration points (MRN seismic record and material parameters of Table 1) 


\subsection{Energy dissipation and vulnerability assessment}

For in-plane mechanisms, the second step of the proposed method states to identify intrinsically vulnerable and non-vulnerable elements. Thus, the central vault and the apse vault can be considered as intrinsically vulnerable, while the main façade, the right and left chapels and the apse walls can be regarded as initially non-vulnerable. After this definition, DED values have to be considered. Results are displayed in $\left[\mathrm{N} / \mathrm{mm} / \mathrm{m}^{3}\right]$ since referred to energy per unit of fractured surface divided by the volume of the considered macro-element. As shown in Table 4 , the central vault is affected by the highest DED value; for that reason and due to its intrinsic nature it can be then considered the first vulnerable macro-element. Moreover, the left and right chapel, the longitudinal walls 45 cm-thick and the façade have respectively 20,15 and $5 \mathrm{~N} / \mathrm{mm} / \mathrm{m}^{3}$.

Out-of-plane mechanisms have been identified for the church in the left and right chapels, in the apse and in the façade (Fig. 13) for the model with material properties reported in Table 1. Thus, these elements are considered vulnerable as understandable from the crack pattern given by plastic strain energy vectors. Analysts could possibly perform non-linear kinematic analyses to have an additional evaluation of their seismic vulnerability. 
Table 3 Failure modes for the macro-elements identified in the case study: plastic strain vectors distribution and DED values

\begin{tabular}{|c|c|c|c|c|c|}
\hline Macro-element & $\begin{array}{l}\text { Surveyed failure } \\
\text { mode }\end{array}$ & Real damage & $\begin{array}{c}\text { Corresponding collapse } \\
\text { mechanism from (Papa et al. } \\
\text { 2011) }\end{array}$ & DED hierarchy & Plastic strain vectors distribution \\
\hline Central vault & In-plane (shear) & & & $\approx 28 \mathrm{~N} / \mathrm{mm} / \mathrm{m}^{3}$ & 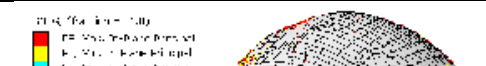 \\
\hline Ext.walls $\mathrm{t}=30 \mathrm{~cm}$ & $\begin{array}{l}\text { In-plane shear } \\
\text { mechanism; } \\
\text { Out-of-plane } \\
\text { incipient } \\
\text { overturning; } \\
\text { internal adjacent } \\
\text { arch detachment } \\
\text { from wall }\end{array}$ & & & $\approx 20 \mathrm{~N} / \mathrm{mm} / \mathrm{m}^{3}$ & 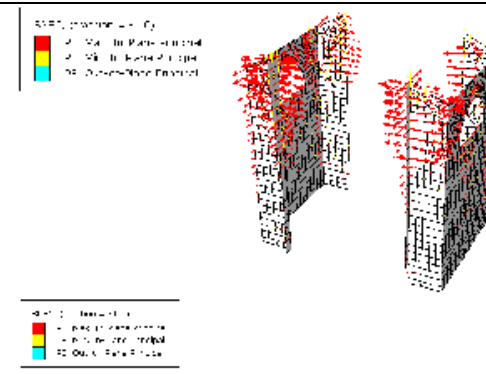 \\
\hline Apse vault & $\begin{array}{l}\text { Out-of-plane } \\
\text { overturning }\end{array}$ & & & $\approx 3 \mathrm{~N} / \mathrm{mm} / \mathrm{m}^{3}$ & 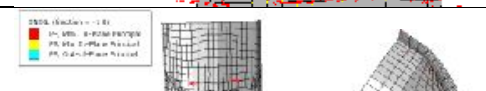 \\
\hline
\end{tabular}




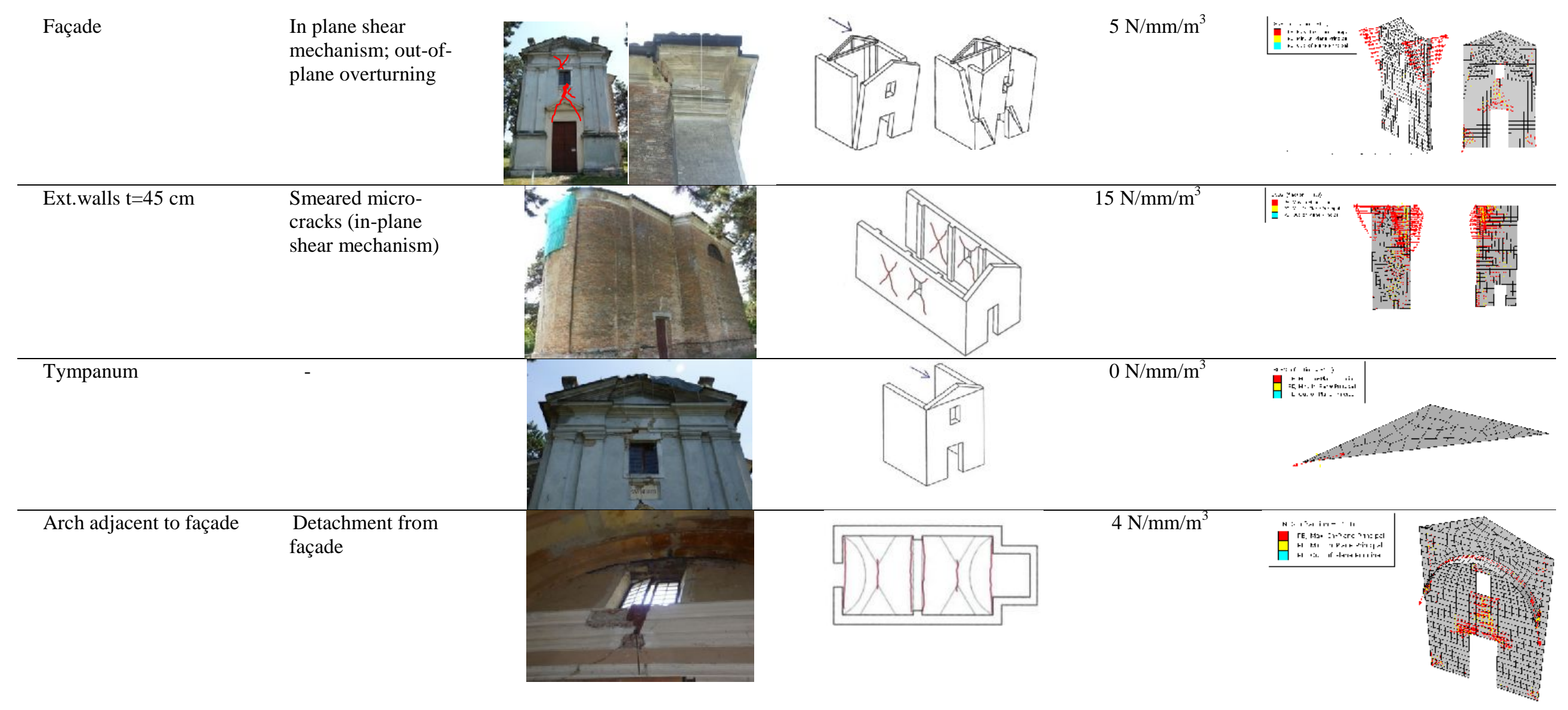


A scale of vulnerability can be compiled, giving information about a possible priority of interventions to improve the church seismic response (Table 4). The scale is compiled giving more vulnerability to intrinsically vulnerable elements (vaults) first, then proceeding with DED values for in-plane and out-of-plane mechanisms. Between the two intrinsically vulnerable elements, central vault and apse vault, the first would require a more urgent rehabilitation. An advantage introduced with the proposed method is that for a same category of failure, such as that of vaults, it is possible to quantitatively assess the seismic vulnerability in terms of dissipated energy in case of multiple vaults. With the unique evaluation of cracks distribution, it would be more difficult to give a quantitative estimation.

The $30 \mathrm{~cm}$ thick walls are affected by out-of-plane and in-plane behavior, with high DED value (Fig. 13). However, their DED value is higher than the average one computed for the whole church equal to $12 \mathrm{~N} / \mathrm{mm} / \mathrm{m}^{3}$. External walls with thickness $45 \mathrm{~cm}$ are considered less vulnerable than the external walls with thickness $30 \mathrm{~cm}$ since their response is only in-plane. The arch adjacent to the façade has a similar DED value as that of the apse vault.

The main façade has a low DED value with respect to the average one of the whole church and undergoes outof-plane response: the combination of both data identifies an undesirable situation. The occurred damage is actually relevant, but concentrated in small areas above and below the opening. Indeed, the DED of this macroelement is low due to a unique concentrated crack in a big volume.

From the analysis of the tympanum, the absence of significant cracks emerged and DED values near zero were obtained (Table 3). Indeed, in the actual response the typical overturning mechanism was not activated.

Table 4 Scale of vulnerability of macro-elements in the as-built configuration

\begin{tabular}{lcc} 
Macro-element & $D E D\left(\mathrm{~N} / \mathrm{mm} / \mathrm{m}^{3}\right)$ & Failure modes \\
\hline Central vault & 28 & In plane \\
\hline Apse vault & 3 & In plane \\
\hline Ext.walls $\mathrm{t}=30 \mathrm{~cm}$ (left-right chapels) & 20 & In plane - Out of plane \\
\hline Ext.walls $\mathrm{t}=45 \mathrm{~cm}$ & 15 & In plane \\
\hline Arch adjacent to façade & 4 & - \\
\hline Façade & 5 & In plane - Out of plane \\
\hline Apse (walls) & 0 & - \\
\hline Tympanum & 0 & -
\end{tabular}

\subsection{Considerations on the energy dissipation and parametric analyses}

Fig. 14 displays the DED evolution for the mechanical parameters reported in Table 1 during the MRN (Mirandola) earthquake. After approximately ten seconds of time-history analysis, the maximum value of dissipation energy is attained, and it remains constant, since peak accelerations are passed, after about twelve seconds.

The macro-elements that dissipated major energy are the central vault, followed by the left and right chapels, $30 \mathrm{~cm}$ thick. Indeed, the central vault collapsed (Fig. 6) and the right-left façades (Fig. 9) were strongly damaged by the ground motion, both in-plane and out-of-plane with incipient overturning. 


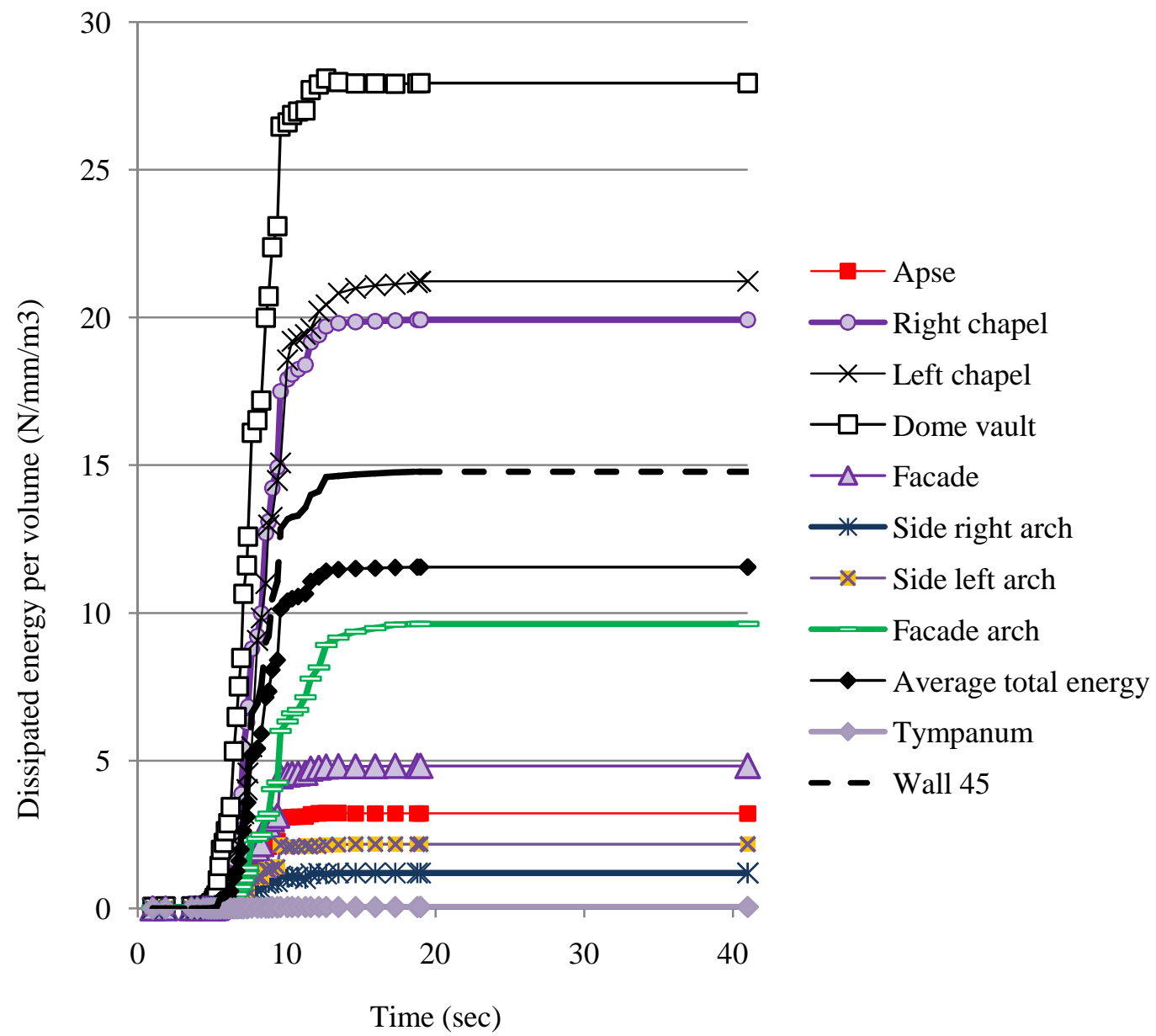

Fig. 14 DED evolution for the church subjected to Mirandola acceleration time history $-\mathrm{f}_{\mathrm{t}}=0.05 \mathrm{MPa}$,

$\mathrm{FE}=0.001 \mathrm{~N} / \mathrm{mm}$, quadratic S8R elements

DED values registered for the left/right façades overcome the average damage of the church, obtained as the total dissipation energy divided by the overall masonry volume. The same occurs for the $45-\mathrm{cm}$ thick longitudinal walls, with a DED value of about $15 \mathrm{~N} / \mathrm{mm} / \mathrm{m}^{3}$ for the initial case. The values of dissipated energy of remaining macro-elements or arches stand below this. The main façade and the apse, although noticeably damaged, exhibit low dissipation energy density, since cracks have large extension, but are few and the involved volume is large (Fig. 7, Fig. 8). The remaining elements, which are the side arches (intended as arches adjacent to left and right façades) and the internal façade arch are reported for comparison purposes: one can see that the value of the façade arch is quite high as demonstrated by the real occurred damage.

It is not straightforward to associate the amount of dissipated energy to out-of-plane or to in-plane mechanism. For that reason, the crack pattern must be considered in addition to identify the damage extent and to compile a scale of vulnerability.

Fig. 15 shows the dissipation energy per unit volume, over time, for different values of fracture energy (FE). Linear 4-nodes and quadratic 8-nodes elements are taken into account in the parametric analysis. One can notice that the evolution of damage is nearly the same, so the FE values do not modify d the relative ratio between the DED of the several macro-elements of the church; although generally the absolute DED values increase if the fracture energy decreases: that is caused by the increasing number of cracked elements in each macro-element. 


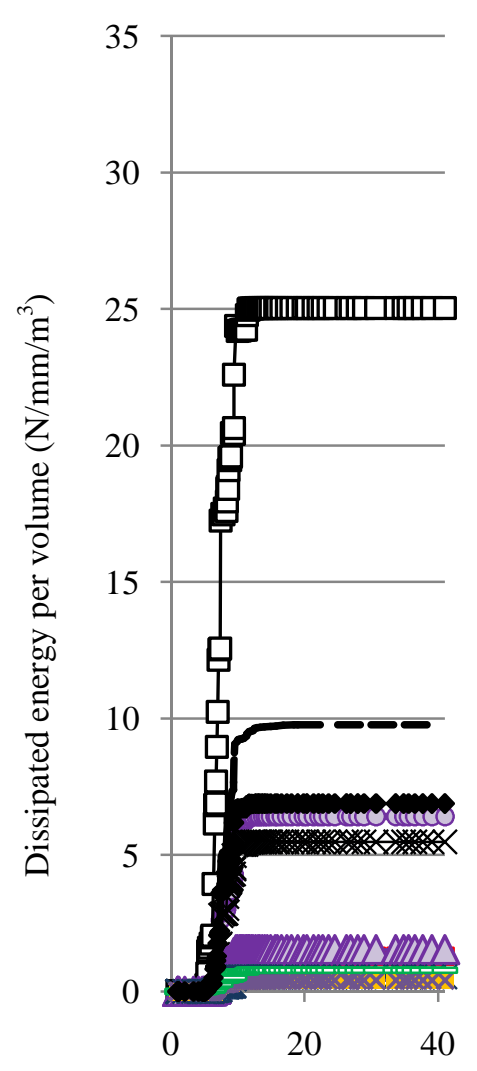

Time (sec)

$\mathrm{f}_{\mathrm{t}}=0.10 \mathrm{MPa}$,

$\mathrm{FE}=0.10 \mathrm{~N} / \mathrm{mm}, \mathrm{S} 4 \mathrm{R}$

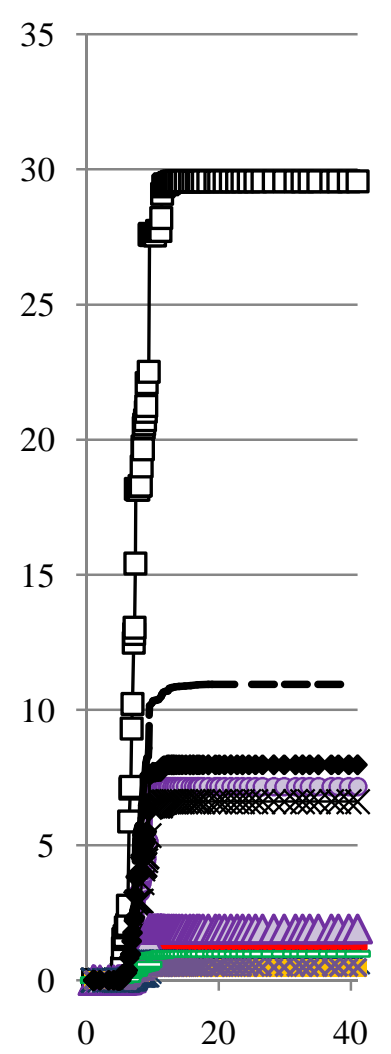

Time (sec)

$\mathrm{f}_{\mathrm{t}}=0.10 \mathrm{MPa}$,

$\mathrm{FE}=0.05 \mathrm{~N} / \mathrm{mm}, \mathrm{S} 4 \mathrm{R}$

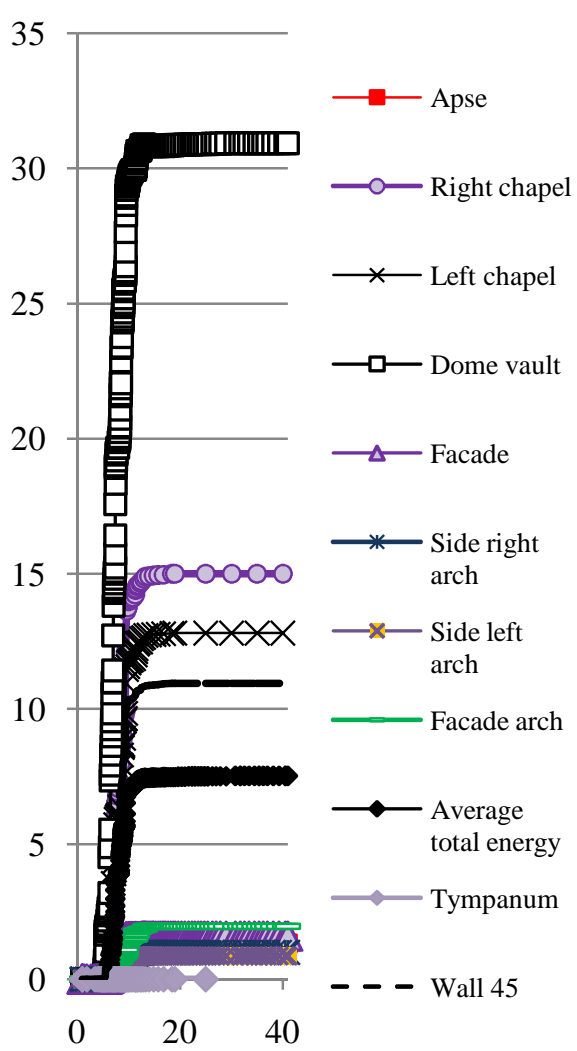

Time (sec)

$\mathrm{f}_{\mathrm{t}}=0.10 \mathrm{MPa}$,

$\mathrm{FE}=0.01 \mathrm{~N} / \mathrm{mm}, \mathrm{S} 8 \mathrm{R}$

Fig. 15 DED evolution (MRN) for different values of fracture energy

Parametric analysis with different values of compressive strength, performed to detect its influence, showed no relevant differences in the response, confirming that the mechanical properties that most affect the masonry behavior are tensile strength $f_{t}$ and fracture energy FE. The plastic strains vectors, which identify the cracks direction, are depicted in Fig. 16. It can be observed that the contour plots change in a negligible fashion supposing different $f_{t}$ and FE values. The cracks are concentrated on the intersecting walls in the lateral façades, as actually occurred in terms of out-of-plane mechanisms. Moreover, in all four cases of Fig. 16, cracks at the intersection of the main façade with longitudinal walls are visible and reproduce the real situation shown in Fig. 7(c), in the incipient overturning of the façade limited in a small length from the top of the wall (Fig. 13).

The analyses were performed also by keeping constant the mechanical properties and changing the acceleration time-history (Mirandola, MRN, Moglia, MOG0, Novellara, NVL, § 5.4). The DED values are scaled to the overall average one, taken equal to 1 (Table 5). Thus, for instance, the central vault is always affected by the highest DED value. The results are very similar for the actions characterized by a similar PGA (Table 2), MRN and MOG0: for instance the main façade and the apse vault have about $20 \%$ of the average DED. By contrast, if the PGA is lower, some failures are not even activated (e.g. for the NVL in the side arches and the façade), some others overestimated (apse). However, the most dissipating macro-elements for MRN and MOG0 dissipate more also in NVL (right chapel with 0.85 and the dome vault with 10.87). Thus, the energy dissipation is comparable for actions that have a similar PGA. The failure modes associated with these actions are however very similar to Fig. 16 in terms of damage pattern. 


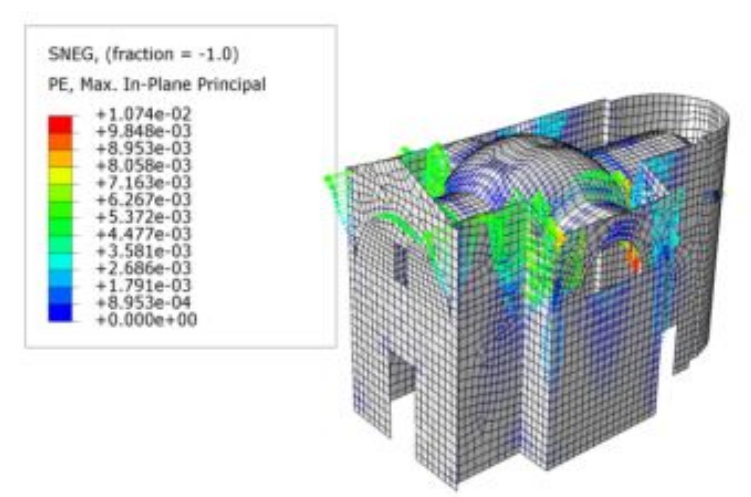

$\mathrm{f}_{\mathrm{t}}=0.10 \mathrm{MPa}, \mathrm{FE}=0.01 \mathrm{~N} / \mathrm{mm}, \mathrm{S} 8 \mathrm{R}$

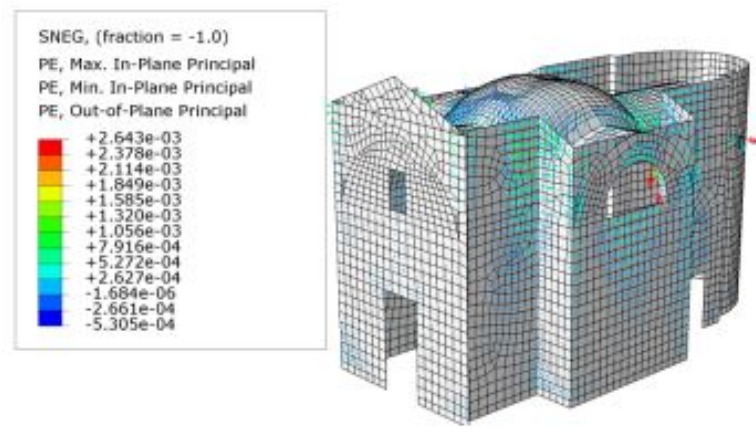

$\mathrm{f}_{1}=0.10 \mathrm{MPa}, \mathrm{FE}=0.10 \mathrm{~N} / \mathrm{mm}, \mathrm{S} 4 \mathrm{R}$

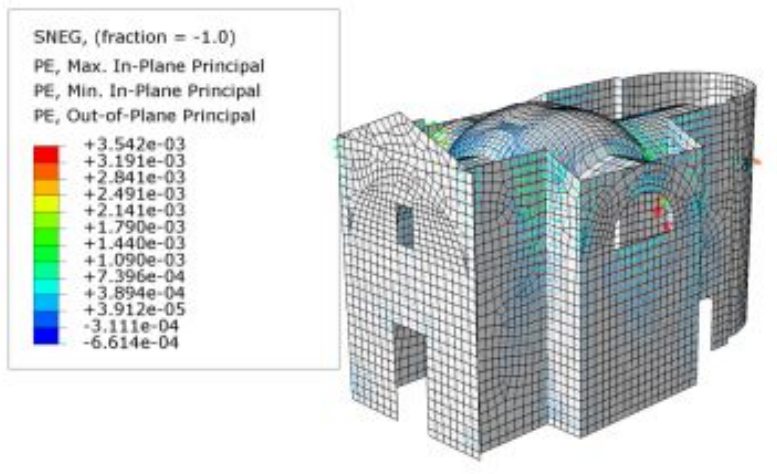

$\mathrm{f}_{\mathrm{t}}=0.10 \mathrm{MPa}, \mathrm{FE}=0.05 \mathrm{~N} / \mathrm{mm}, \mathrm{S} 4 \mathrm{R}$

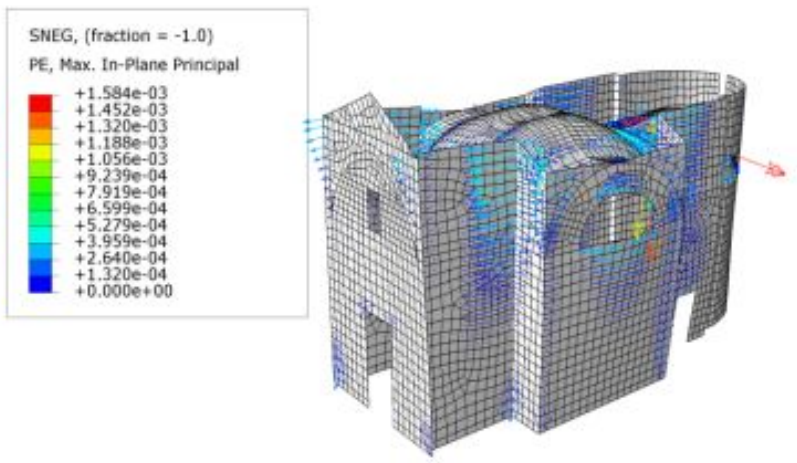

$\mathrm{f}_{1}=0.15 \mathrm{MPa}, \mathrm{FE}=0.50 \mathrm{~N} / \mathrm{mm}, \mathrm{S} 4 \mathrm{R}$

Fig. 16 Direction of plastic strains vectors for different masonry mechanical properties (MRN)

Table 5 Rates of dissipated energy for each macro-element/arch in S.Venerio church (with respect to the average energy/volume $-\mathrm{S} 4 \mathrm{R}, \mathrm{f}_{\mathrm{t}}=0.15 \mathrm{MPa}, \mathrm{FE} 0.5 \mathrm{~N} / \mathrm{mm}$ )

\begin{tabular}{ccccccccccc}
$\begin{array}{c}\text { Seismic } \\
\text { record }\end{array}$ & PGA $(g)$ & $\begin{array}{c}\text { All } \\
\text { average }\end{array}$ & $\begin{array}{c}\text { Apse } \\
\text { vault }\end{array}$ & $\begin{array}{c}\text { Facade } \\
\text { arch }\end{array}$ & $\begin{array}{c}\text { Side } \\
\text { right arch }\end{array}$ & $\begin{array}{c}\text { Side } \\
\text { left arch }\end{array}$ & $\begin{array}{c}\text { Right } \\
\text { chapel }\end{array}$ & $\begin{array}{c}\text { Left } \\
\text { chapel }\end{array}$ & $\begin{array}{c}\text { Dome } \\
\text { vault }\end{array}$ & Façade \\
\hline MRN & 0.212 & 1.00 & 0.24 & 0.01 & 0.05 & 0.02 & 0.69 & 0.63 & 4.64 & 0.21 \\
\hline MOG0 & 0.236 & 1.00 & 0.19 & 0.02 & 0.03 & 0.04 & 0.72 & 0.63 & 5.76 & 0.17 \\
\hline NVL & 0.055 & 1.00 & 1.90 & 0.00 & 0.00 & 0.00 & 0.85 & 0.31 & 10.87 & 0.00
\end{tabular}

\subsection{Strengthening techniques and rehabilitation strategy}

The improvement obtained with strengthening measures, for the sake of brevity, is taken into account using modified geometric or mechanical properties of existing materials. That choice is part of the rehabilitation strategy illustrated in $\S 2$, where a target parameter is varied to reduce damage and dissipated energy density in vulnerable macro-elements. Let us assume improved mechanical properties for tensile state of vulnerable elements, as classified in $\S 5.3$. In particular, a fracture energy per unit of surface of $0.1 \mathrm{~N} / \mathrm{mm}$ and tensile strength of $0.2 \mathrm{MPa}$ have been assumed. This reinforced material is adopted for the central vault and the left and right chapels. In addition to the material modification, n. 2 steel $20 \mathrm{~mm}$-diameter tie-rods are designed for the 
façade, to limit the out-of-plane mechanism; n.2 diagonal tie-rods with $25 \mathrm{~mm}$-diameter are also supposed in the

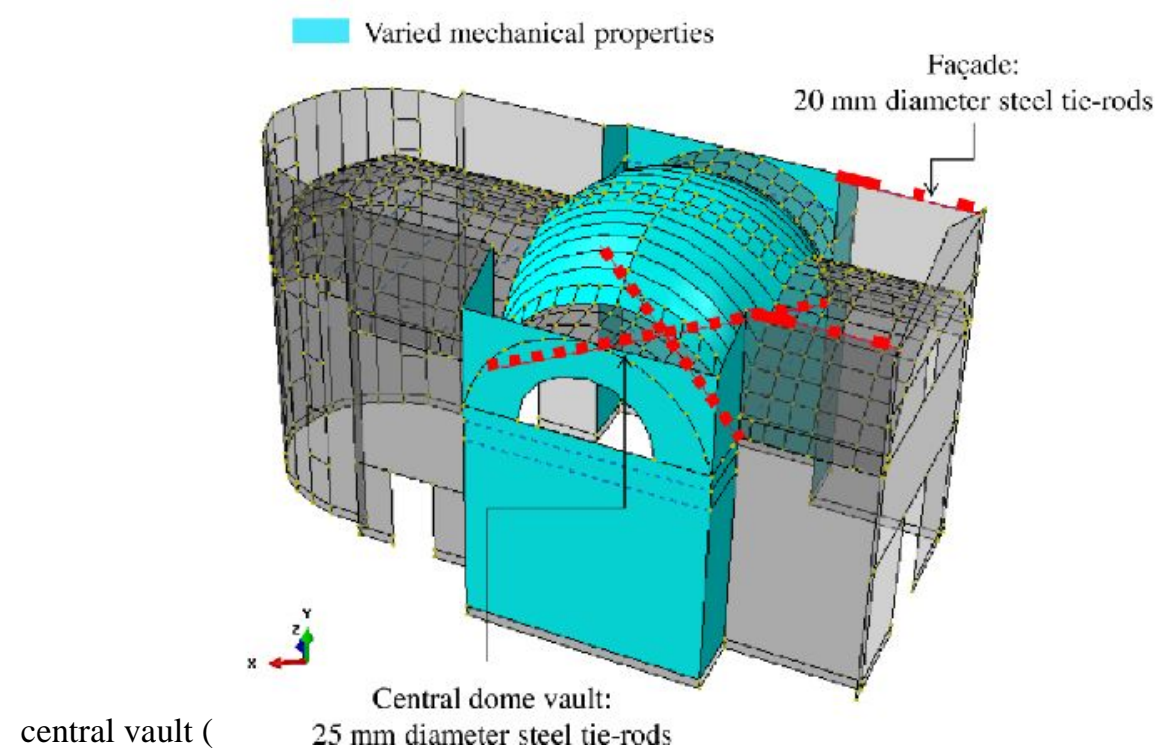

Fig. 17). That is aimed to reduce relative displacements between vault supports.

Results are displayed in Table 6, in terms of dissipated energy (DE) for each macro-element and dissipated energy density (DED) obtained by DE divided by the corresponding volume. The overall average energy density decreased by $28 \%$, particularly for the reduced damage $(-61 \%)$ obtained in the central vault. A strong reduction of energy also occurred for the left $(-57 \%)$ and right $(-48 \%)$ chapel walls, diminishing damages related to outof-plane failure (Fig. 18). For these walls, still out-of-plane mechanisms seem to be possible in the intersection with 45-cm thick walls, aspect that could be reduced with additional tie-rods. No significant reduction was registered for the longitudinal $45 \mathrm{~cm}$-thick walls (-10\%). Nevertheless, in the façade the DED decreased by $37 \%$ and the maximum plastic strain decreased by about $40 \%$ (maximum strain vector at the top of the façade equal to $7.8 \mathrm{e}-3$ in the as-built case compared to $4.6 \mathrm{e}-3$, Fig. 18). This was due to the reduction of the out-of-plane mechanism, eased by the two steel tie-rods. Moreover, in the apse vault a negligible DED reduction of $4 \%$ occurred.

Several criteria for considering the strengthening techniques efficient can be addressed to have similar DED values for all macro-elements equal to the overall average DED, or values that do not overcome a specific percentage of the overall average DED, or a fixed reduction of DED for each macro-element.

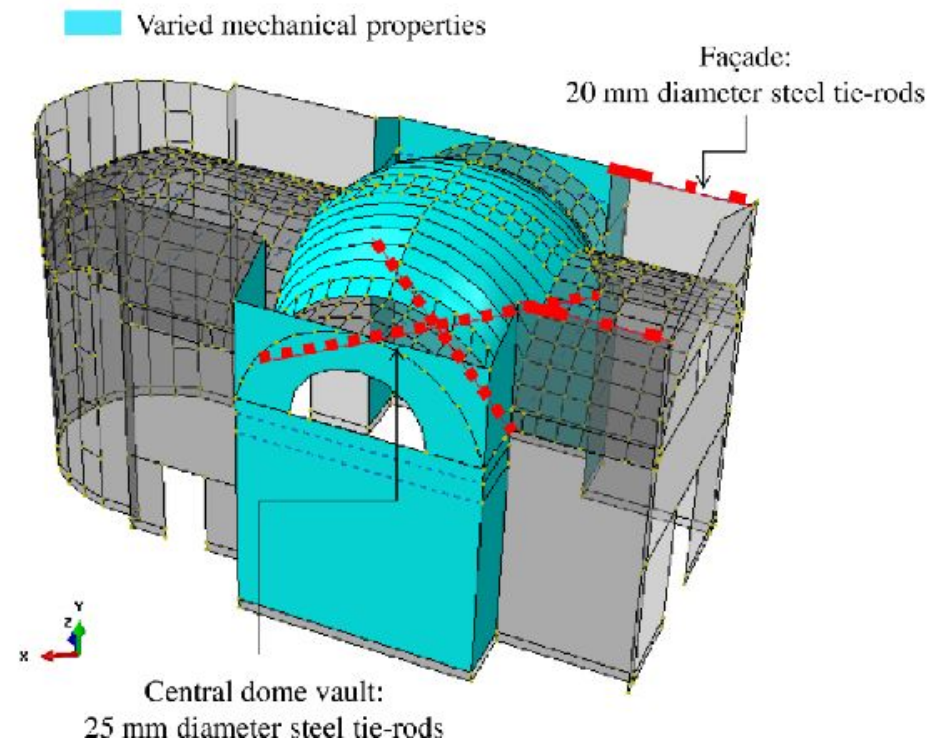

Fig. 17 Example of rehabilitation strategy: varied mechanical properties and steel tie-rods installment

Table 6 Rehabilitation strategy results: comparisons in terms of dissipated energy (DE), dissipated energy density (DED) between the as-built configuration and the rehabilitated one with percentage of DED reduction 


\begin{tabular}{l|ll|c|ll|c} 
& \multicolumn{2}{|c|}{$D E(\mathrm{~N} / \mathrm{mm})$} & Volume & \multicolumn{2}{c|}{ DED $\left(\mathrm{N} / \mathrm{mm} / \mathrm{m}^{3}\right)$} & \\
& As-built & Reinf. & $\left(\mathrm{m}^{3}\right)$ & As-built & Reinf. & \% DED red. \\
Whole church & 3104.54 & 2227.49 & 268.86 & 11.55 & 8.29 & -28 \\
Dome vault & 96.23 & 37.33 & 3.45 & 27.93 & 10.84 & -61 \\
Left chapel & 735.86 & 313.13 & 34.67 & 21.22 & 9.03 & -57 \\
Right chapel & 690.67 & 359.20 & 34.67 & 19.92 & 10.36 & -48 \\
Wall 45 & 521.82 & 471.07 & 35.31 & 14.78 & 13.34 & -10 \\
Façade & 249.73 & 156.36 & 51.88 & 4.81 & 3.01 & -37 \\
Apse vault & 171.63 & 164.97 & 53.33 & 3.22 & 3.09 & -4 \\
Tympanum & 0.10 & 0.52 & 7.58 & 0.01 & 0.07 & +423
\end{tabular}

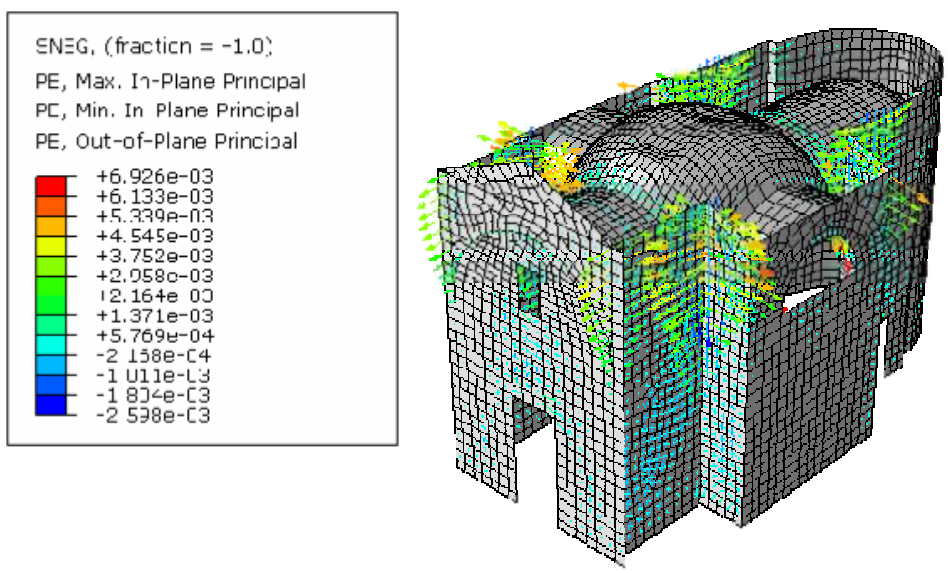

Fig. 18 Plastic strain vectors distribution in the rehabilitated case ( $\max =0.0046$ at the top of the façade)

Other target parameters might be varied, for instance the central vault thickness (for instance with stiffening lightweight concrete and FRP). Fig. 19 shows the improvement achieved if one assumes a vault thickness of 12 $\mathrm{cm}$ instead of $6 \mathrm{~cm}$, properly adapting the corresponding seismic mass $\left(\mathrm{FE}=0.5 \mathrm{~N} / \mathrm{mm}, \mathrm{f}_{\mathrm{t}}=0.15 \mathrm{MPa}\right.$, seismic record MRN). The value of the dissipated energy density changes from about 23 to $15 \mathrm{~N} / \mathrm{mm} / \mathrm{m}^{3}$, resulting in a reduction of the work required to the vault of $35 \%$.

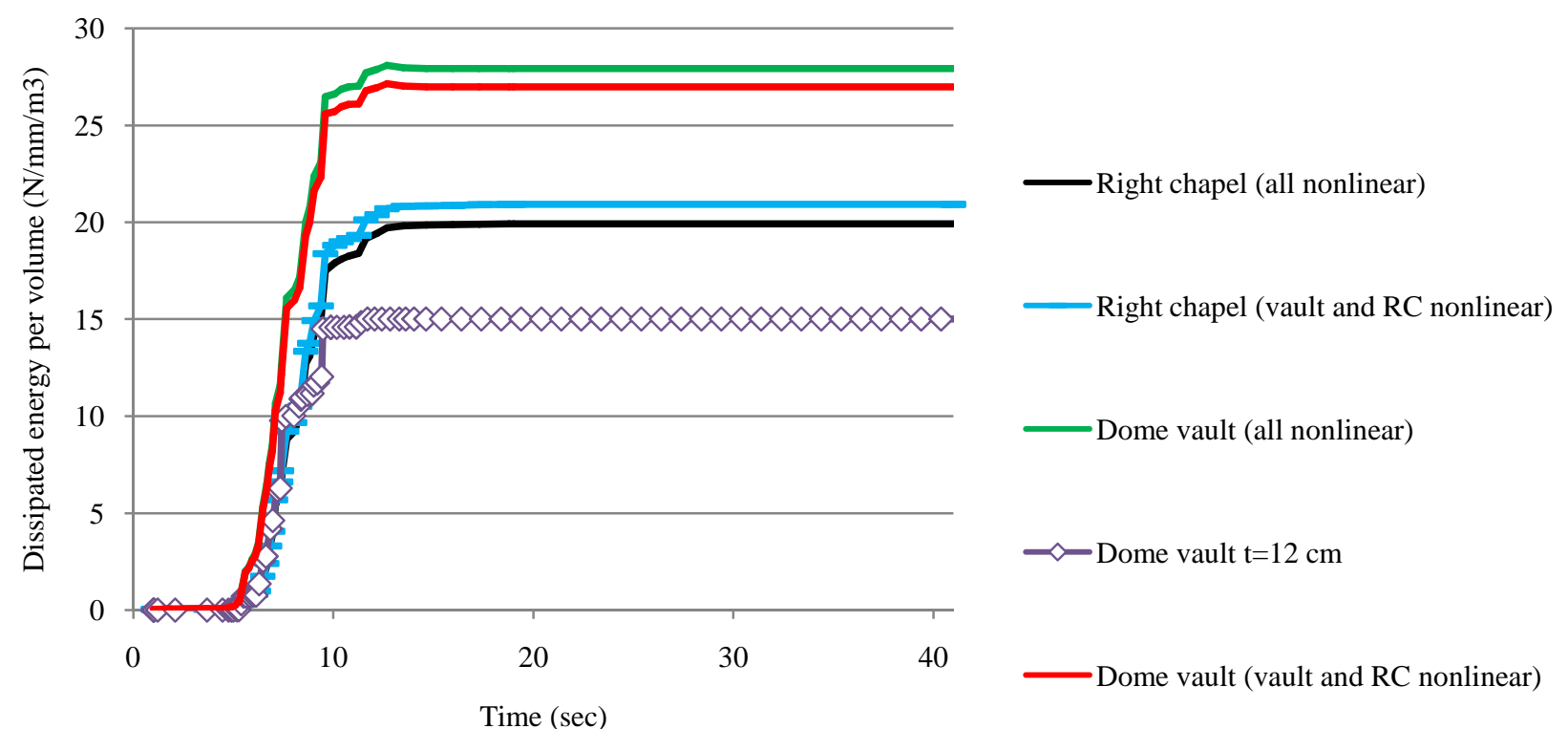

Fig. 19 Dissipated energy per unit volume with all nonlinear macro-elements and just the vault and the right chapel walls (RC) nonlinear - vault equivalent thickness: $12 \mathrm{~cm}$ 


\subsection{Effect of "limited" non-linearity to a reduced number of macro-elements.}

It could be interesting to investigate the situation for which only some macro-elements are analyzed in nonlinear range. The purpose is of significantly reducing the computing time without compromising correctness of results. Both vault and right chapel are assumed to be non-linear ( $\mathrm{FE}=0.5 \mathrm{~N} / \mathrm{mm}, \mathrm{f}_{\mathrm{t}}=0.15 \mathrm{MPa}$, seismic record MRN, Fig. 19). Graphs show how results are not influenced by the nonlinear behavior of the adjacent macroelements. Such aspect is particularly significant, since it strongly reduces one of the limitations of the proposed method, with a computational time reduced by a factor 1:10. Nevertheless, this result does not have to be considered as general, since the vulnerable macro-elements are not known in advance and that can provide undesirable results.

\section{FINAL CONSIDERATIONS AND LIMITATIONS OF THE METHOD}

The method is computationally expensive, for the necessities of taking into account both material nonlinearities and multiple acceleration time-histories. Nevertheless, it has been shown that if one considers just some macroelements characterized by nonlinear behavior, results in terms of dissipated energy do not sensitively change. Although there is not a relevant dependence of outcomes on mechanical properties, the latter are difficult to estimate, especially due to difficulties to perform experimental tests on historic masonry. Finally, the number of acceleration time histories, for which the analysis can be considered reliable, is not known in advance: that aspect may further increase the computational time. However, unlike the push-over analysis, the procedure is capable of predicting the damages without missing the time information, namely the evolution of damage over time.

\section{CONCLUSIONS}

The proposed strategy investigates the damage evolution during earthquakes in masonry churches. With this method, a scale of vulnerability can be compiled for macro-elements that compose the church. This is done considering two factors: the dissipated energy density over time (DED value) and the cracks distribution obtained from non-linear transient analyses. First, in-plane and out-of-plane modes are classified. Out-of-plane modes result in a vulnerable behavior, together with intrinsically vulnerable macro-elements (thin masonry vaults e.g.) subjected to shear mechanisms and high dissipated energy values. By contrast, in-plane response of intrinsically non vulnerable elements (such as thick walls) is not considered vulnerable. The method is an additional procedure to the existing ones, concerning 3D FE analyses, discrete or limit analysis on rigid blocks. It provides a further check parameter, the dissipated energy for each macro-element, which supports the vulnerability assessment of macro-elements and failure modes of the same category.

The single nave St. Venerio church was analyzed to apply the proposed method on a real case. Without knowing damages in advance, the method has been able to suggest a scale of vulnerability depending on the failure modes and the DED values for each macro-element. Thus, the central vault was classified by the method as the most vulnerable macro-element. A possible strengthening technique was proposed in terms of improved mechanical tensile properties and steel tie-rods. A strong reduction of DED occurred for the more vulnerable macro-elements and in the main façade the maximum plastic strain decreased by about $40 \%$, due to the reduction of the out-of-plane mechanism caused by the tie-rods. The method was established to be sensitively dependent neither on the nonlinear mechanical properties, in particular fracture energy and tensile strength, nor on the acceleration time-history, when PGA is similar.

\section{ACKNOWLEDGEMENTS}

The author wishes to thank Ing. Bellesia for providing information about the St. Venerio church. In addition, she thanks the Department of Structural Dynamics at RWTH in Aachen, DAAD association and ReLUIS Consortium (AT 1.1 masonry structures - U.R. Pisa) for having supported and funded this work. 


\section{REFERENCES}

Circolare esplicativa del 02.02.2009 contenente "Istruzioni per l'applicazione delle nuove norme tecniche per le costruzioni di cui al D.M. 14.01.2008" (In italian).

NTC2008 (1/14/2008): Approvazione delle Nuove Norme Tecniche per le Costruzioni. In : Gazzetta Ufficiale della Repubblica Italiana n. 29, February, 28th 2008, Supplemento Ordinario n. 30.

Abaqus CAE 6.12, User's and Theory Manuals.

Accelerograms Database of seismic shocks on May, 29th2012, Emilia Romagna region (Italy). Department of Italian Civil Protection (2012). Available online at http://www.mot1.it/randownload/EN/index.php.

Andreini, M.; De Falco, A.; Giresini, L.; Sassu, M. (2014): Structural damage in the cities of Reggiolo and Carpi after the earthquake on May 2012 in Emilia Romagna. In Bulletin of Earthquake Engineering 12 (5), pp. 24452480 .

Betti, M.; Vignoli, A. (2008): Modelling and analysis of a Romanesque church under earthquake loading: Assessment of seismic resistance. In Engineering Structures 30 (2), pp. 352-367.

D'Ayala, D.; Speranza, E. (2003): Definition of Collapse Mechanisms and Seismic Vulnerability of Historic Masonry Buildings. In Earthquake Spectra 19 (3), pp. 479-509.

De Lorenzis, Laura; DeJong, Matthew; Ochsendorf, John (2007): Failure of masonry arches under impulse base motion. In Earthquake Engng Struct. Dyn. 36 (14), pp. 2119-2136. DOI: 10.1002/eqe.719.

Doglioni, F.; Moretti, A.; Petrini, V. (1994): Le Chiese e i terremoti. Lint. Trieste.

Grimaldi, A.; Luciano, R.; Sacco, E. (1992): Nonlinear dynamic analysis of masonry structures via FEM. In Computing methods in applied sciences and engineering, pp. 373-382.

Hilleborg, A.; Modeer, M.; Petersson, P. E. (1976): Analysis of Crack Formation and Crack Growth in Concrete by Means of Fracture Mechanics and Finite Elements. In Cement and Concrete Research 6, pp. 773-782.

Lagomarsino, S. (1998): A new methodology for the post-earthquake investigation of ancient churches. In Proc. of the 11th European Conference on Earthquake Engineering, p. 67.

Lagomarsino, S.; Brun, S.; Giovinazzi, S.; Idri, C.; Penna, A.; Podestà, S. et al. (Eds.) (1999): Modelli di calcolo per il miglioramento sismico delle chiese. L'ingegneria sismica in Italia. Torino.

Lagomarsino, S.; Podest a, S. (2004a): Seismic Vulnerability of Ancient Churches: I. Damage Assessment and Emergency Planning. In Earthquake Spectra 20 (2), pp. 377-394.

Lagomarsino, S.; Podest a, S. (2004b): Seismic Vulnerability of Ancient Churches: II. Statistical Analysis of Surveyed Data and Methods for Risk Analysis. In Earthquake Spectra 20 (2), pp. 395-412.

Lee, J.; Fenves, G. L. (1998): Plastic-Damage Model for Cyclic Loading of Concrete Structures. In Journal of Engineering Mechanics 124 (8), pp. 892-900.

Lourenço, P. B. (1996): Computational strategies for masonry structures. Ph.D. Thesis. Delft University of Technology, Delft.

Lourenço, P. B.; Mendes, N., Ramos, L., Oliveira, D.V. (2011): Analysis of Masonry Structures Without Box Behavior. In International Journal of Architectural Heritage 5 (4-5), pp. 369-382.

Lourenço, P. B.; Roque J.A. (2006): Simplified indexes for the seismic vulnerability of ancient masonry buildings. In Construction and Building Materials 20 (4), pp. 200-208.

Lubliner, J.; Oliver, J.; Oller, S.; Oñate, E. (1989): A Plastic-Damage Model for Concrete. In International Journal of Solids and Structures 25, pp. 299-329.

Mele, E.; De Luca, A. (1999): Behavior and modelling of masonry church buildings in seismic regions. 
Milani, E.; Milani, G.; Tralli, A. (2008): Limit analysis of masonry vaults by means of curved shell finite elements and homogenization. In International Journal of Solids and Structures 45 (20), pp. 5258-5288. DOI: 10.1016/j.ijsolstr.2008.05.019.

Milani, G. (2013): learned after the Emilia-Romagna, Italy, 20-29 May 2012 earthquakes: A limit analysis insight on three masonry churches. In Engineering Failure Analysis 34, pp. 761-778.

Milani, G.; Lourenço, P. B.; Tralli, A. (2006): Homogenised limit analysis of masonry walls. Part I: failure surfaces. In Computers \& Structures 84, pp. 166-180.

Papa, S.; Di Pasquale, G.; Podestà, S.; Brignola, A. (2011): Manuale per la compilazione della scheda per il rilievo del danno ai beni culturali, Chiese, Modello A-DC.

Peña, F.; Meza, M.; Chavez, M. (Wrocław Poland, 2012): Macroelement identification of masonry churches by means of their dynamic properties. In Structural Analysis of Historical Constructions, pp. 333-340.

Roca, P.; Cervera, M.; Gariup, G.; Pelá, L. (2010): Structural Analysis of Masonry Historical Constructions. Classical and Advanced Approaches. In Archives of Computational Methods in Engineering 17 (3), pp. $299-325$.

Sassu, M.; Andreini, M.; De Falco, A. (Eds.) (2012): Damage mechanisms as seismic transducers in historic centres: the example of San Pio delle Camere after 2009 earthquake in Abruzzo (Italy). 15th World Conference Earthquake Engineering. Lisboa.

Schubert, P. (1988): The influence of mortar on the strength of masonry. In Proc. 8th Int. Brick and Block Masonry Conf., Ed. J.W. de Courcy, Elsevier Applied Science, London, pp. 162-174.

Van der Pluijm, R. (1992): Material properties of masonry and its components under tension and shear. In Proc. 6th Canadian Masonry Symposium, pp. 675-686.

Wawrzynek, A.; Cincio, A. (2005): Plastic-damage macro-model for non-linear masonry structures subjected to cyclic or dynamic loads. In Proc. of Conf. Analytical Models and New Concepts in Concrete and Masonry Structures, AMCM'2005, Gliwice, Poland. 